\title{
المفاهيم العددية بين واقع استيعاب طلاب المرحلة الابتدائية ومعتقدات معلميهم بالمملكة العربية السعودية نحو
}

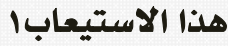

\author{
إبراهيم رفعت عثمان * ومسفر بن سعود السلولي وخالد حلمي خشان \\ جامعة الملك سعود، الرياض، المملكة العربية السعودية
}

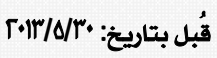

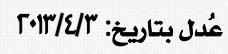

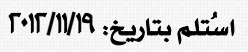

هدفت الدراسة إلى التعرف على مدى استيعاب طلاب المرحلة الابتدائية للمفاهيم العددية، ومقارنة ذلك بمعتقدات معلميهم حول هذا الاستيعاب. ولتحقيق هذا الهدف تم بناء اختبار مفاهيهي تشخيصي لقياس استيعاب المفاهيم العددية بحيث تقيس مفرداته قدرة الطالب على إدراك معنى

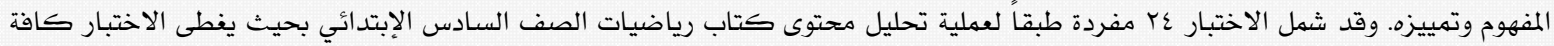

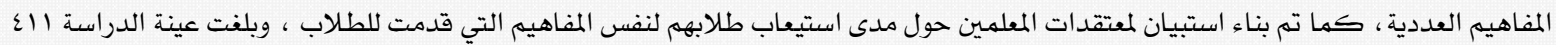

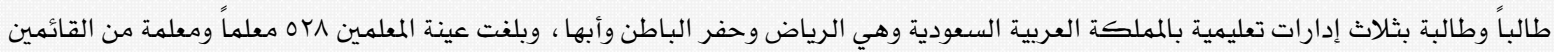

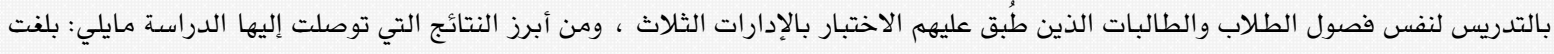

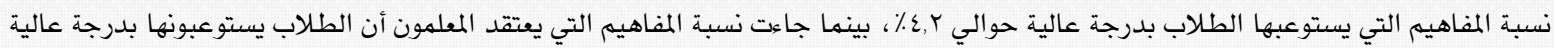

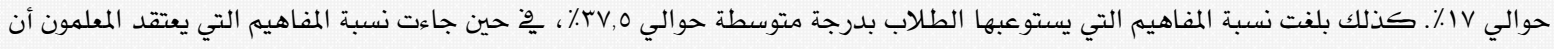

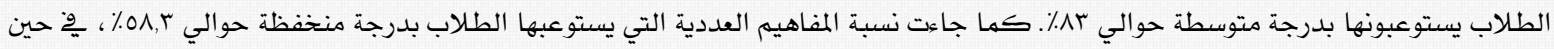

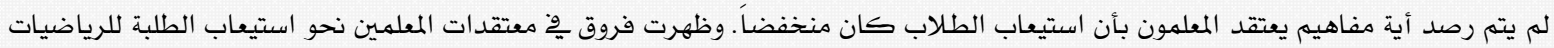

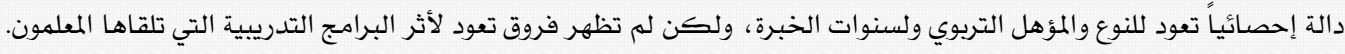
كلمات مفتاحية: المفاهيم العددية، الاستيعاب، معتقدات المعلمين.

\section{N umerical Concepts between the Reality of Elementary Students' Understanding and their Teachers' Beliefs towards this Understanding in Saudi A rabia}

\author{
Ibrahim R. Osman*, Misfer S. El Souloli \& Khaled H. Kashan \\ King Saud University, Riyadh, Kingdom of Saudi A rabia
}

The aim of the study was to identify the understanding of elementary school students of numerical concepts, and the beliefs of their teachers about this understanding. To achievethis goal, the content of the mathematics sixth gradetextbook was analyzed to identify the numerical concepts. Then, a conceptual diagnostic test consisting of 24 multiple-choice questions to measure theunderstanding of numerical concepts was designed. Another questionnaire was built to measure the teachers' beliefs about their students understanding of these concepts. The teachers' questionnaire included 24 concepts as well. The sample size was 1411 male and female students; and the sample size of teachers was 528 mathematics teachers. Both were drawn randomly from three cities in the Kingdom of Saudi A rabia. The test of students showed that about $4.2 \%$ of the numerical concepts werehighly understandable, whereas the questionnaire showed that teachers believed their students understood $17 \%$ of the concepts. Furthermore, students moderately understood about $37.5 \%$ of the concepts, while the questionnaire showed that teachers believed their students moderately undersood about $83 \%$ of the concepts. Moreover, the test showed that about $58.3 \%$ of the concepts were poorly understood, whereas the questionnaire showed that there were no concepts that would be poorly understood. The study found that there were statistically significant differences due to gender, credential, and experience; however, there was no statistically significant difference attributed to training on teachers' beliefs about students' understanding of mathematics.

Keyw ords: numerical concepts, understanding, teachers' beliefs.

*sdscoo@py.ksu.edu.sa

$$
\text { ا تم إنجاز هذا البحث ضمن أعمال المجموعة البحثية الخاصة بتعليم وتعلم العلوم والرياضيات بالمرحلة الإبتدائية وبدعم من مركز التميز البحثي }
$$

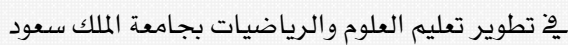


كما تشير دراسـة مداح (1... ؟) إلى أن طلاب المرحلة

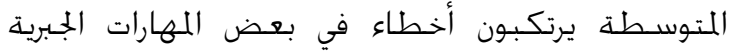

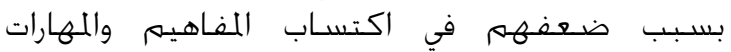

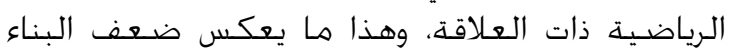

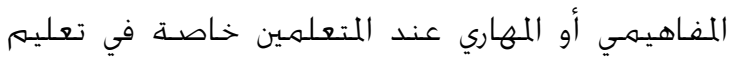

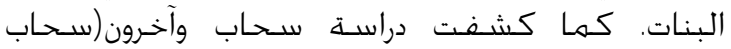

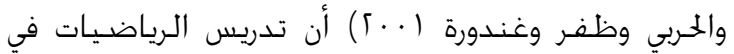

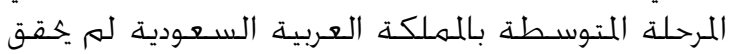

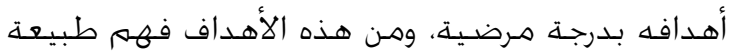

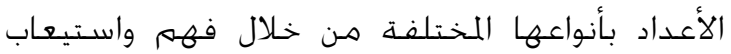

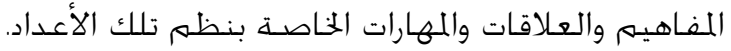

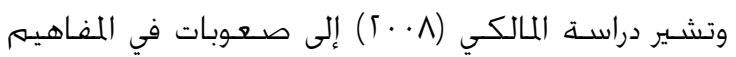

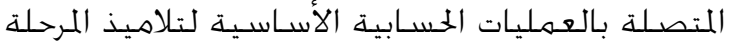
الابتدائية وبالتالي أداء العمليات المرتبطة بتلك المفاهيه.

Levin \& Wadmany, وفي المقابل يشير ليفن ووادماني

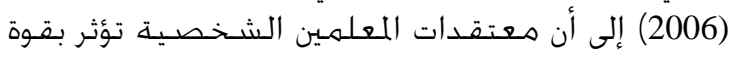

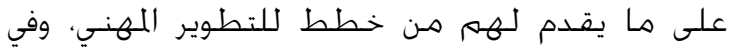

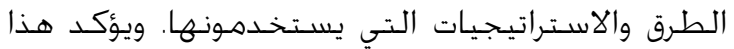

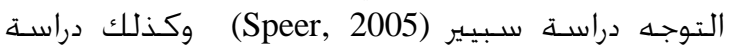
شاهفاراني وسـافيزي (Shahvarani \& Savizi, 2007) في دراس

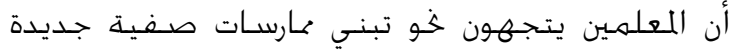

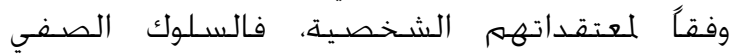

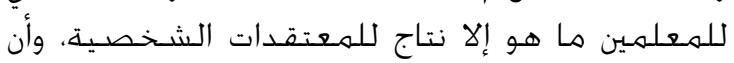

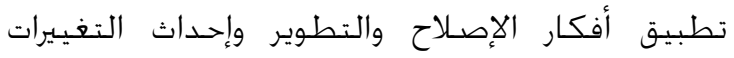

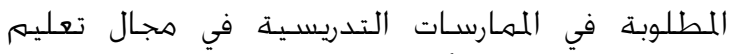

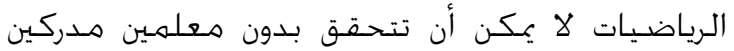

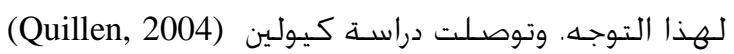

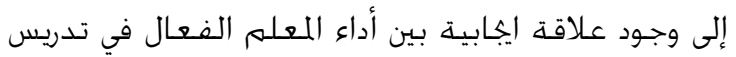

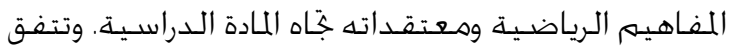

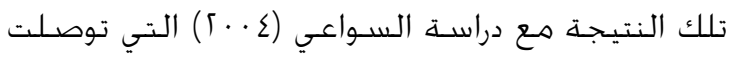

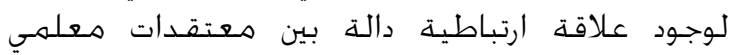

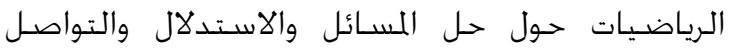

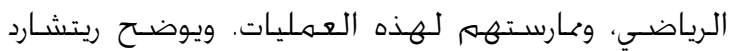

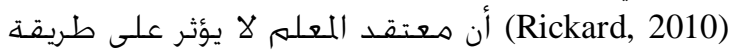

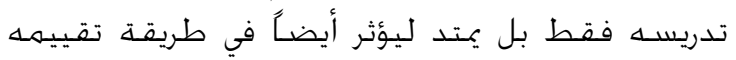

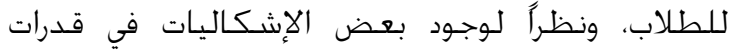

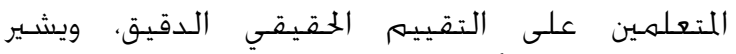

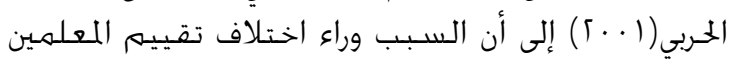

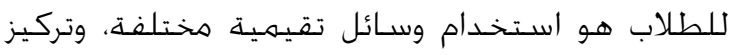

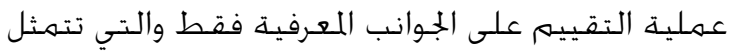

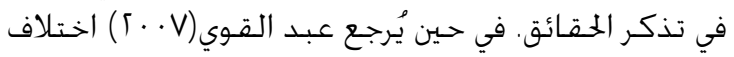

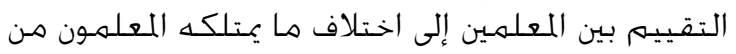

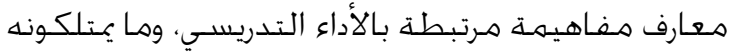

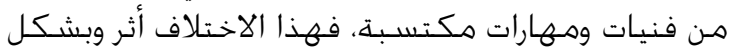

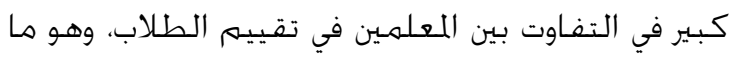

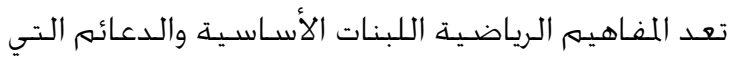
تُبنى عليها المعرفة الرياضية في كافة نظم دراسـة الاستة

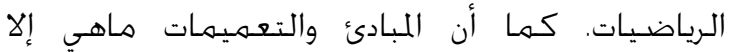

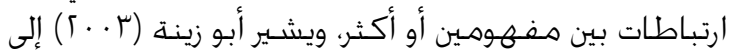

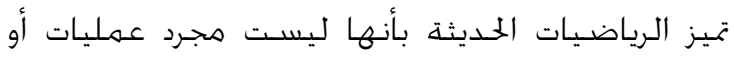

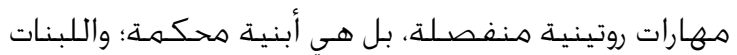

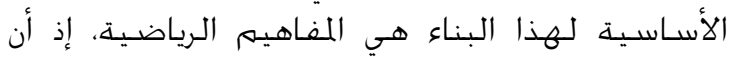

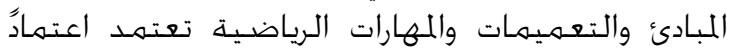
كبيراً على المفاهيم في تكوينها واستـيعابها واكتسـابها.

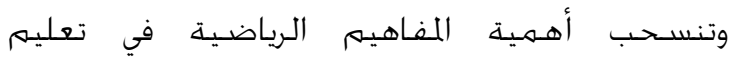

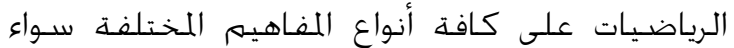

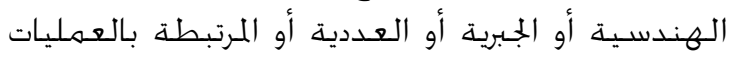

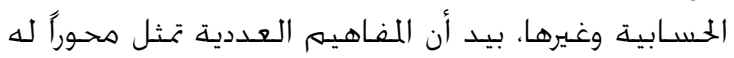

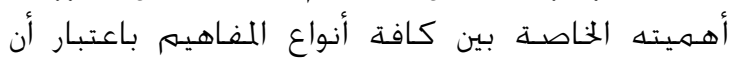

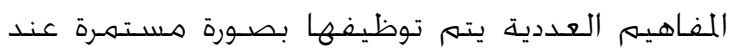

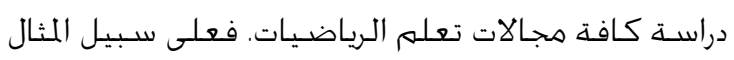

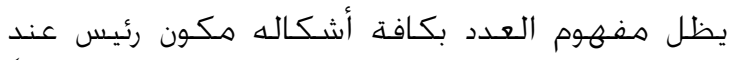

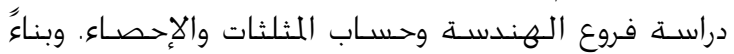

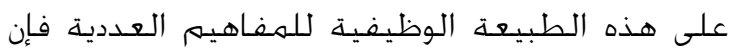

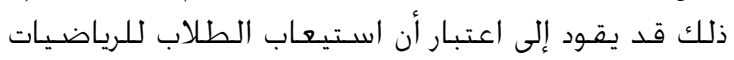

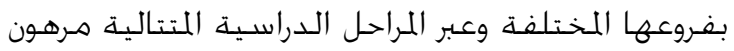
بمدى تمكن الطلاب من استيعاب المفاهيم العددية.

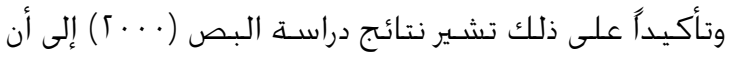

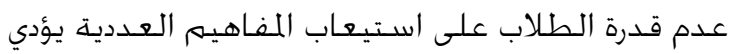
لوجود تصـورات خطأ عن تلك المفاهيم مثل الخلط بين الناهين

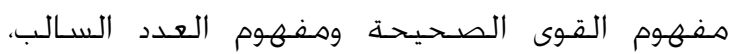

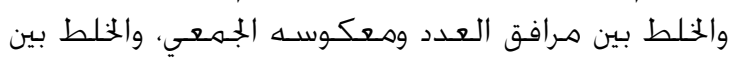

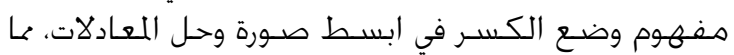

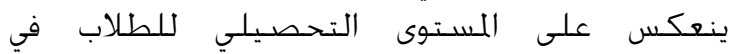

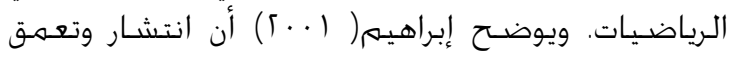

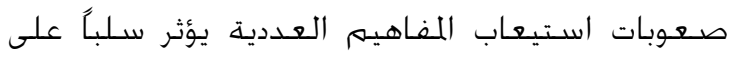

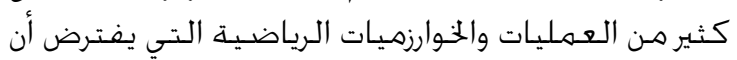

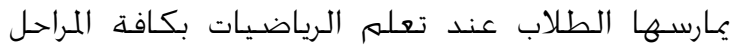

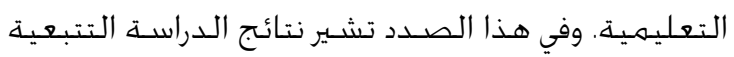

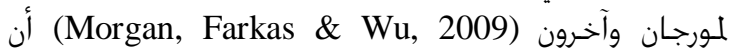

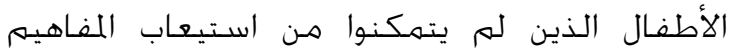

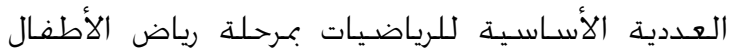

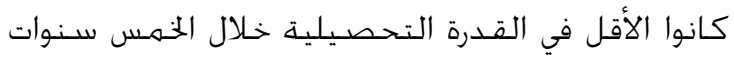

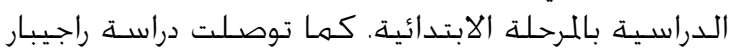
Raghubar, K., Cirino, P., Barnes, M., وآخرونالاسل (Ewing-Cobbs , L., Fletcher, J., \& Fuchs,L. ,2009

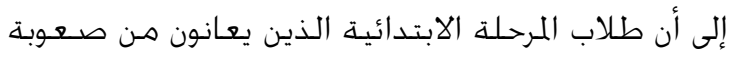

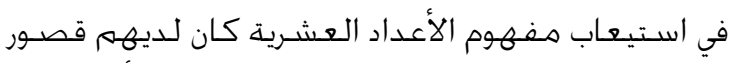

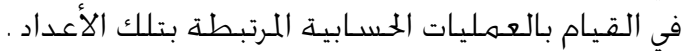


ما أثر الخصائص المرتبطة بمعلمي رياضيات المرحلة

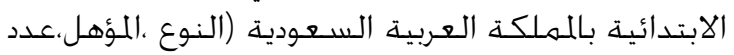

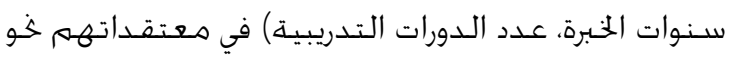

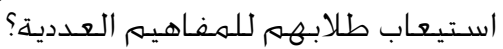

أهـمية الدراســـ

$$
\text { يتوقع أن تفيد الـدراسـة في: }
$$

مسـاعدة القـائمسين على الـبراهـج التدريبية للمعلمـين في

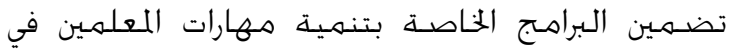

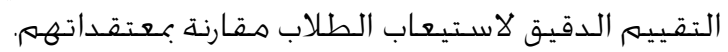
توجيـ انظار الإشـراف التربوي لأهـميـة تقييهم معتقـدات

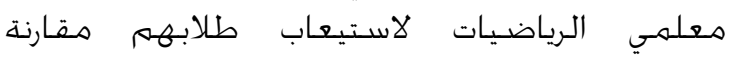
باستيعاب الطلاب بالفعل كمنطلق أسـاسـي في توجيه

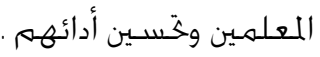

توجيه أنظار المعلمين لمدى التباين بين معتقداتهم الإين

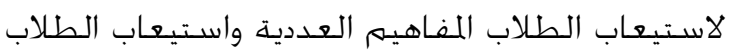

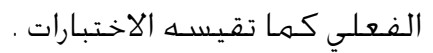

\section{حدود الدراسـة}

تتمثل حـدود الدراسـة في الاقتصـار على محتوي منهـج

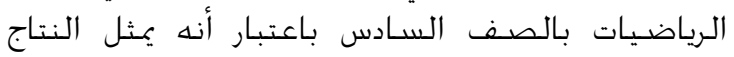

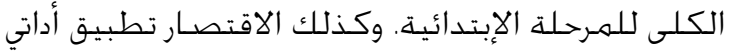

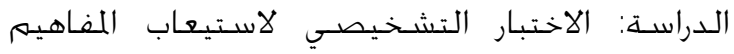

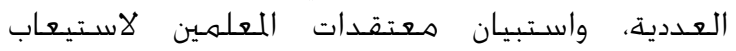

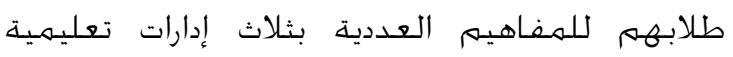

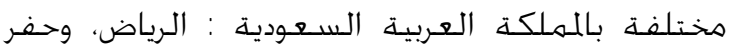

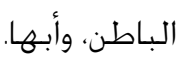

مصطلحات الدراسـة

المفهوم العددي: بالرجوع لتعريفات (حسانين.

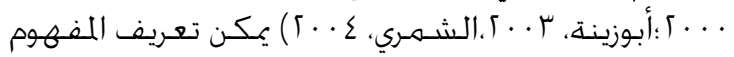

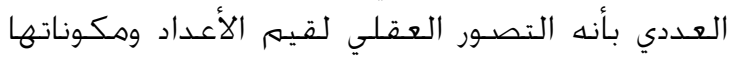

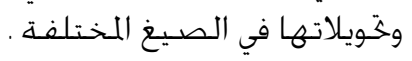

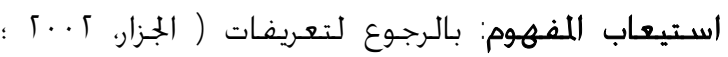

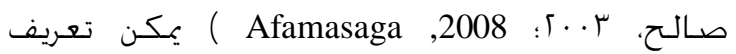

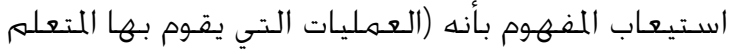

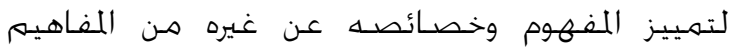
المشابهة إضـافة لاستخـدام معنى وخلئ المفهوم ودلالاته

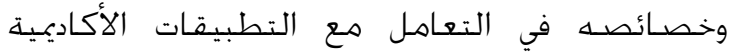
والحياتية ذات الصـلة بالمفهوم ).

معتقدات المعلمين خو استيعاب المفاهيم: بالرجوع

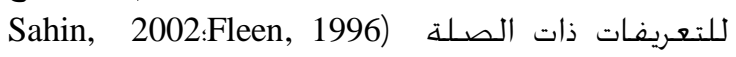
Levin \& Wadmany,2006) :Bullock, \& Stables,

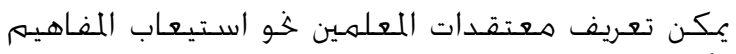

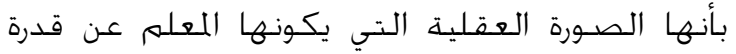

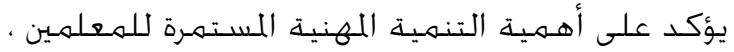

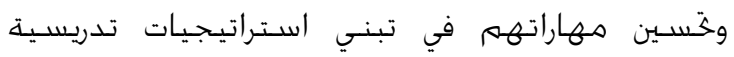

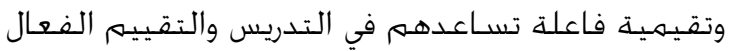
للطلاب.

وبالنظر إلى واقع تقييهم الرياضيات بالمـملكة العربية

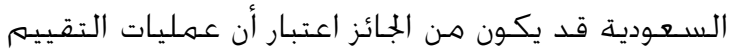

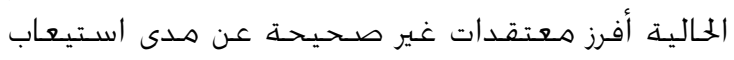

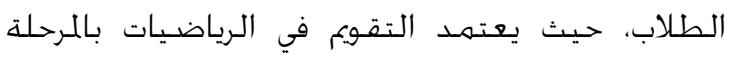

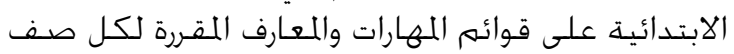

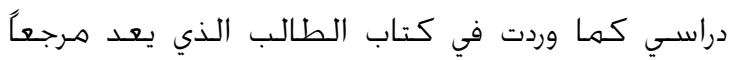

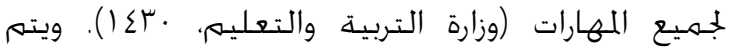

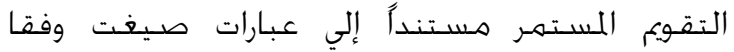

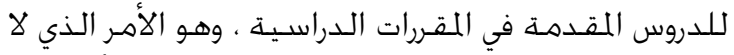

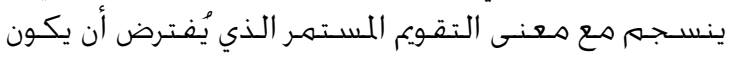

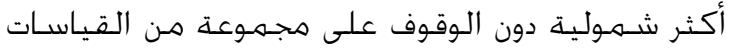

$$
\text { لما ورد في كتاب الطالب نصاً. }
$$

مشـكلة الدراسـة

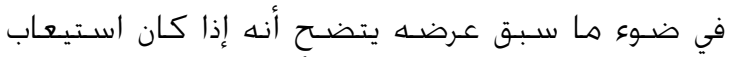

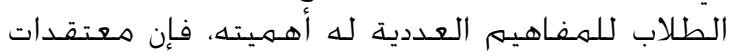

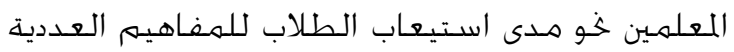

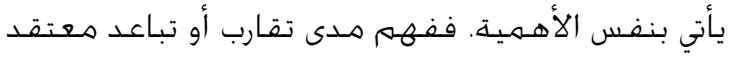

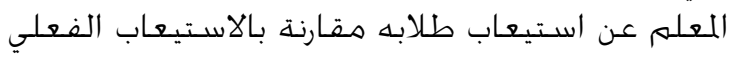

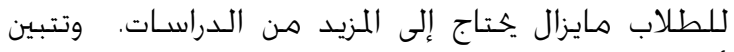

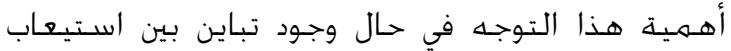

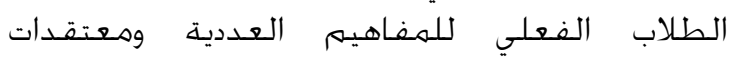

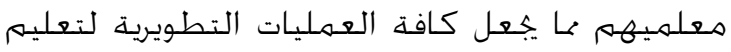

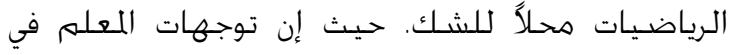

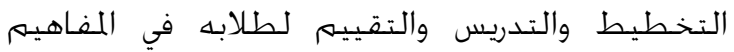

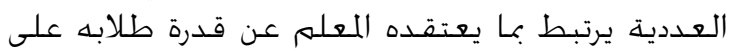

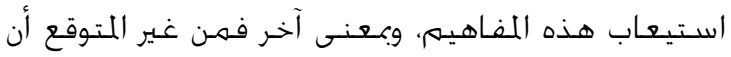

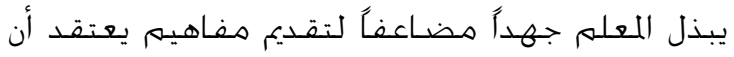

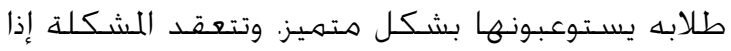

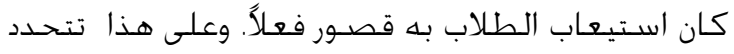
مشـكلة البحـث في الاجابة عن التسـاؤلات التالية:

ما واقع استيعاب طلاب المرحلة الابتدائية بالمملكة

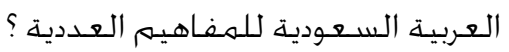
ما واقع معتقـدات معلمي الرياضـيات المرحلة الابتدائية

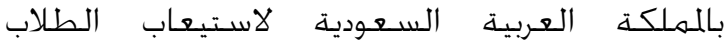

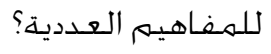
ما وجـه التباين والاتفاق بين استيعاب طلاب المرحلة

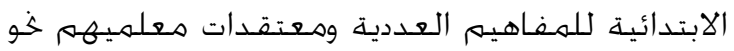

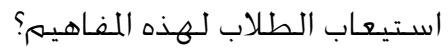




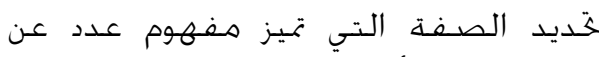

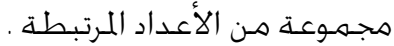

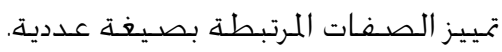
خدديد العلاقة التي تربط بين عددين.

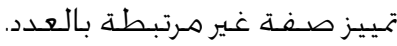
تمييز الأمثلة واللأمثلة المرتبطة بعتبـة بعدد محدد.

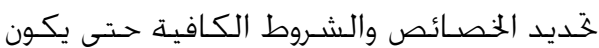

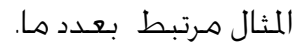

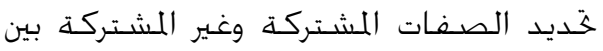
عددين. وتعتبر هذه المؤشـرات هي الأسـاس الذي تعتمـد عليه

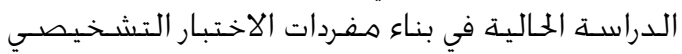
لاستيعاب المفاهيم العددية.

ثانياً: معتقدات معلمي الرياضيات - أنماط معتقدات الماتهات

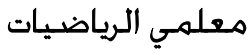

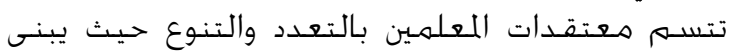

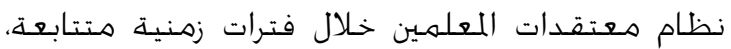

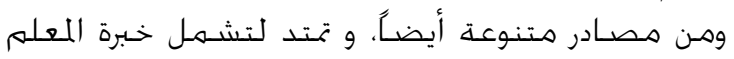

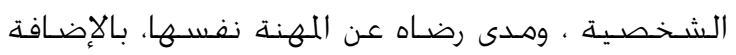

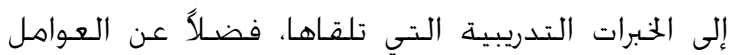

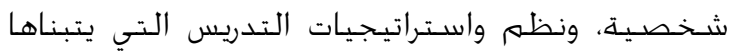

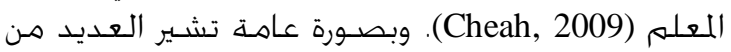

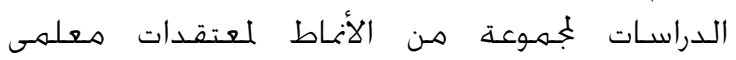
الرياضـيات تتمثل في:

ا. المعتقدات الأكاديمية العامة : وتشهمل

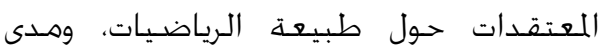

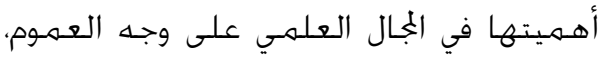

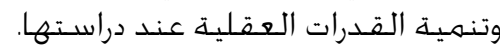

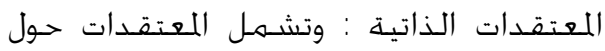

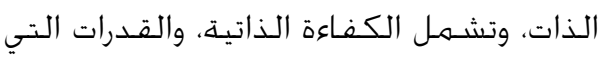

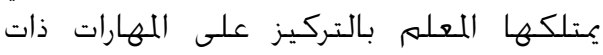
الصـلة بالرياضـيات.

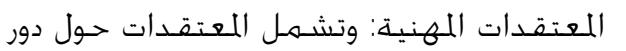

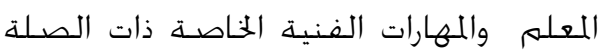
بتعليهم وتعلهم الرياضـيات.

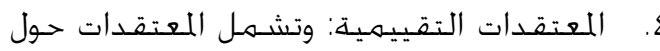

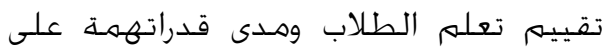

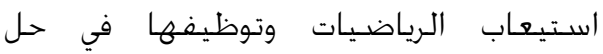

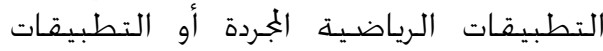
الخياتية.

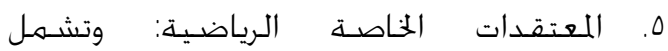

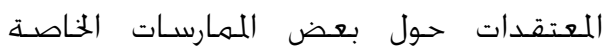

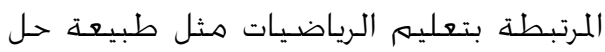
المشكلات.

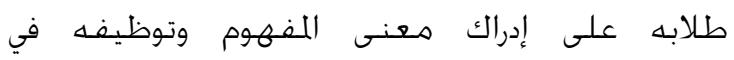

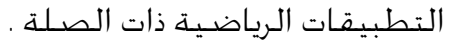

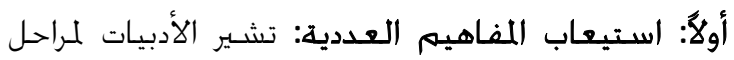

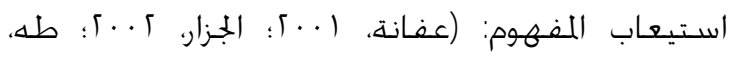

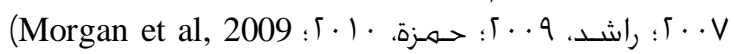

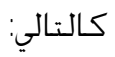

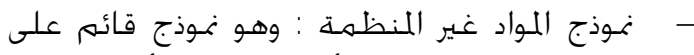

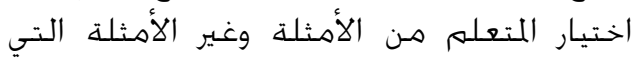

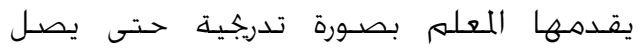

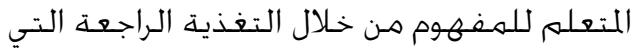

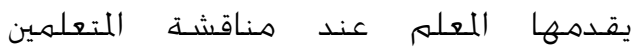
لتصـوراتهم عن المفهوم المراد استيعابه.

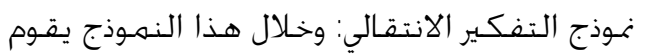

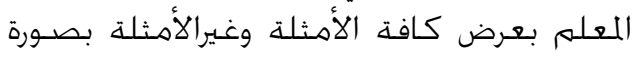

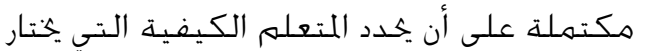

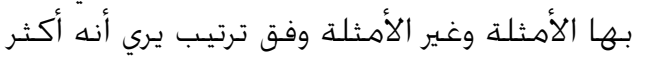

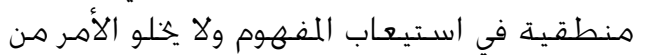

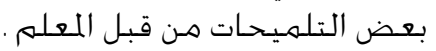

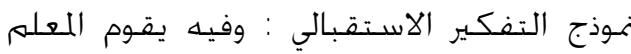

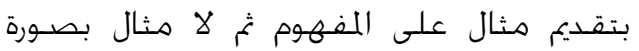

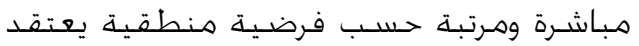

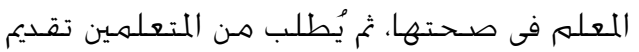

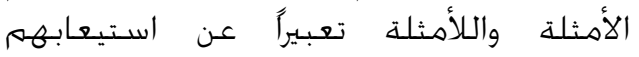

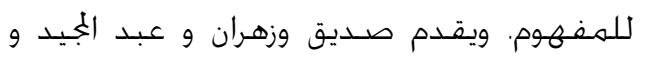

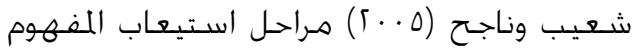
في المراحل التـالية:

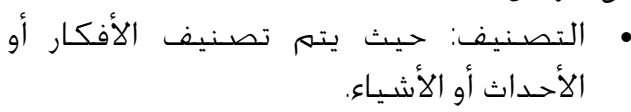

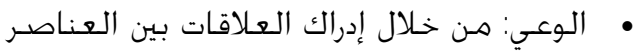

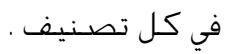

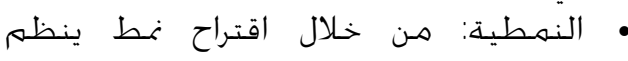

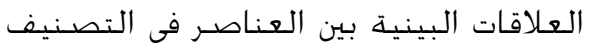
المقترح العات

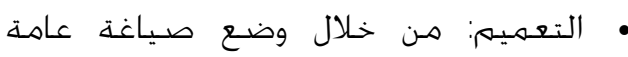

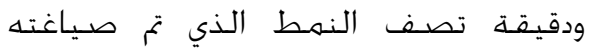

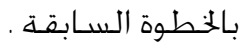

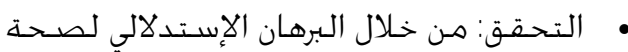

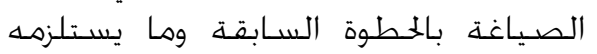
ذلك مـن تدعيم الإثبات بالأهثلة واللأمثلة.

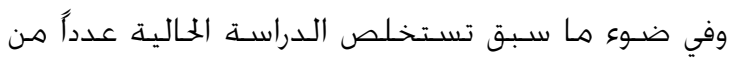

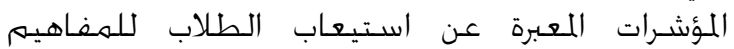

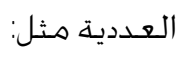
تقديم مثال ينطبق على اللفهروم العددي.

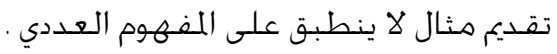


تعزز أو تغير تلك المعتقدات، كما أن معتقدات

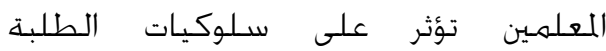

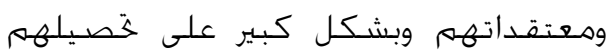
الأكاديمي.

\section{منهج الدراسـة وإجراءاتها}

أدوات الدراسة

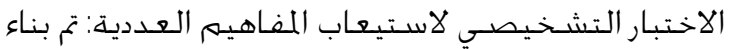

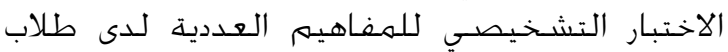
الصف السـادس الابتدائي وفق الخطوات التالية:

مرحلة التحليل: تم خليل محتوى مقرر الرياضيات للصف لإنف

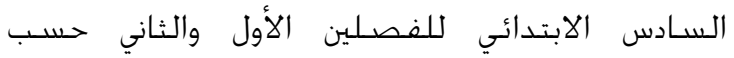

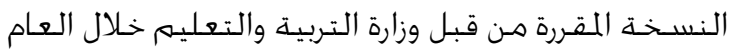

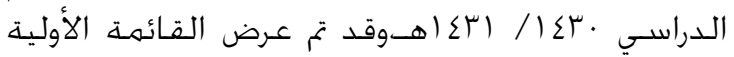

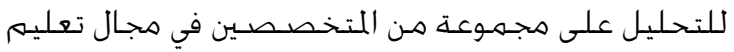

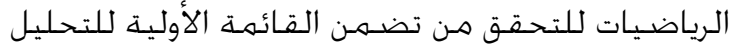

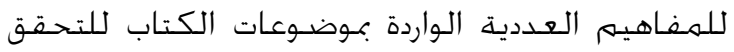

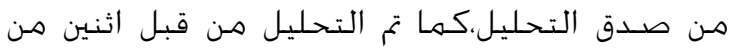

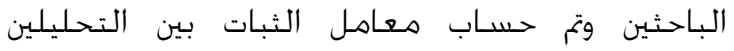

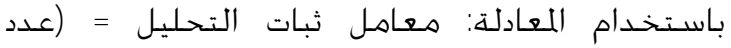

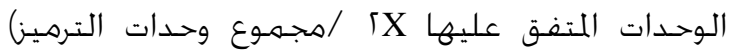

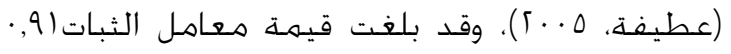

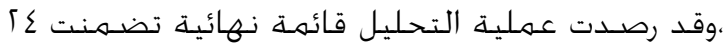
مفهوماً عدديًا.

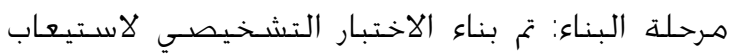
المفاهيم العددية بالرجوع لكافة المفاهيم الواردة بقائمة الإنة

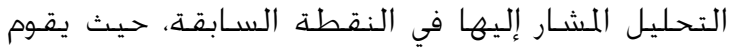

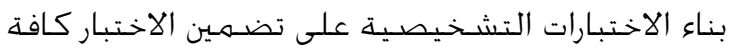

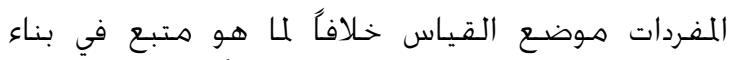

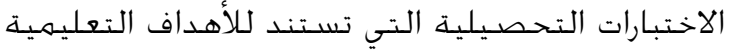
وأهميتها النسبية، وبذلك بلغ عدار النحات مفردات الاختبار

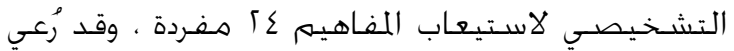
في بناء مفردات الاختبار مايلي: تصعيم المفردات بكيث تقيس قدرة الطالب على إدراك

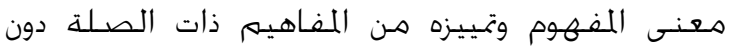
التركيز على تذكر الطالب لتعريف المفهوم نصاً.

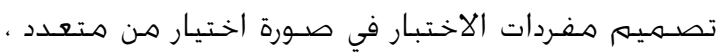

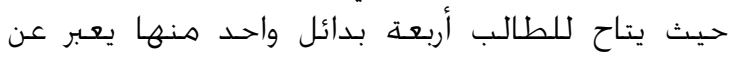

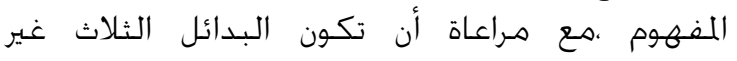
الصـيحة وطيدة الصـلة بالاختيار الصـحيح. مثال : أي من التالي يمثل العدد الكســـي؟

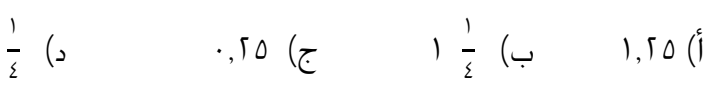

وتندرج الدراسـة الحالية خو نمط المعتقدات الخاصة

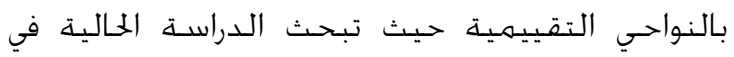
جانب معتقدات المعلمين خو استيعاب المفاهيم العددية.

العوامل المؤثرة في تشكيل معتقدات المعلمين

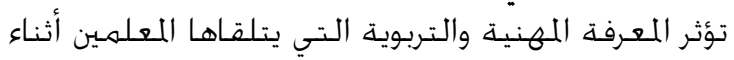

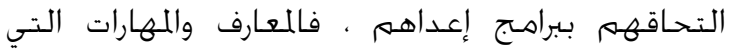
يكتسبونها في مرحلة الإعداد ترتبط بشكل قإعل قوي ببناء

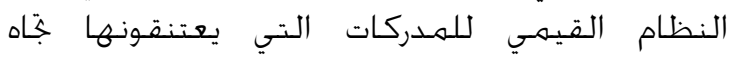
سـلوكهم التدريسي(Turnuklu \& Yesildere, 2007) وفيما يلي خديداً لأثر العواهل التي تسهـم في تشكيل معتقدات المعلمين: - - تشكيل المتقدات من الناحية الزهنية : يشير

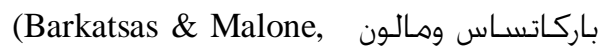

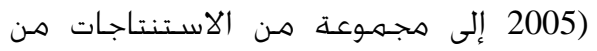

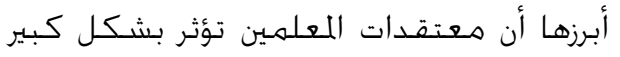

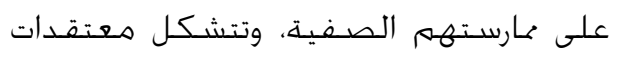

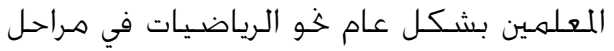

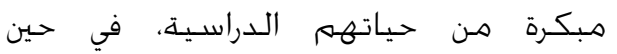

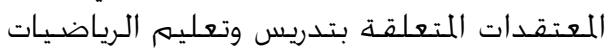
تتشكل أثناء الالتحاق بالمرحلة الجامعية.

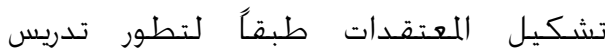

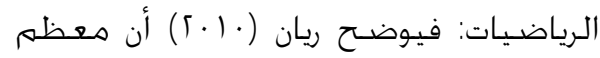

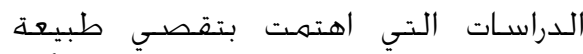
المعتقدات التي يكملها المعلمون سـواء أكان التهان التهات ذلك أثناء الخدمة أم قبلها- مرحلة التعليم التهائ التهان

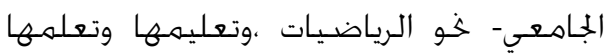

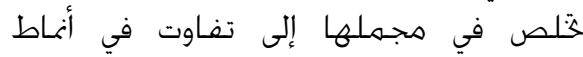

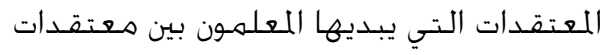

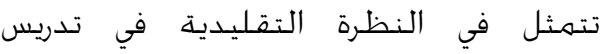
الرياضيات القائمة على مركزية المعلم، وبين النظرة المعاصـرة المتمثلة باللناحي البنائية وحل التحل

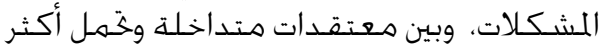
هن نمط.

تشكيل المعتقدات طبقاً لتركيبة المتغيرات التعليمية : اقترح لى (Li, 1999 نموذجاً للعلاقة التهيرات

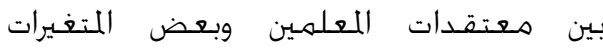
المرتبطة بها كسلوك المعلمين ومعتقدات المينيات

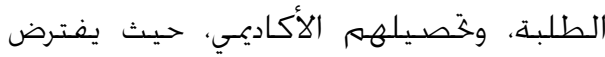
هذا النموذج وجود علاقة تبادلية بين معتقدات

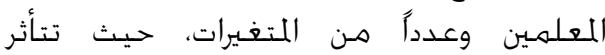
معتقدات المعلمين بسلوكياتهم التدريسية. وكذلك بمعتقدات الطلبة وسـلوكياتهم وختصيلهمه، وفي المقابل فإن سلوكيات المعلمين

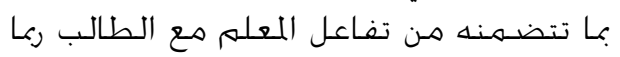




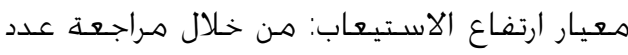

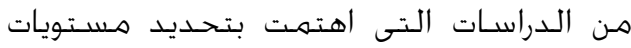

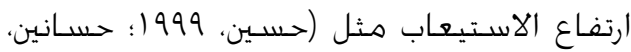

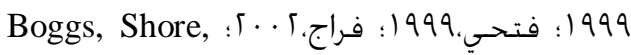
:Yildiran \& Aydin, 2005 :Shore, 2004

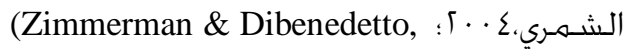

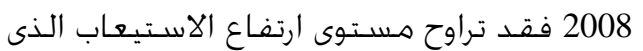

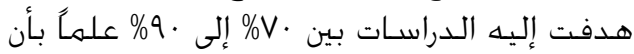

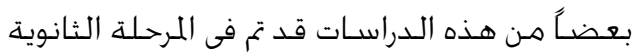

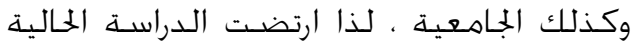

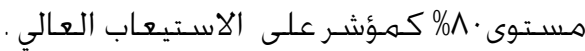

ويلخص جدول ( معايير تفسير درجات الطلاب بالاختبار التشخيصي لاستيعاب المفاهيم العددية.

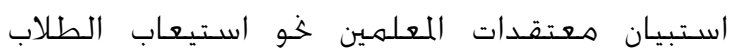

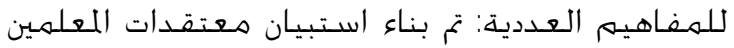
وفقاً لقائمة المفاهيم المشار إليها لـاء في بناء الاحتبار

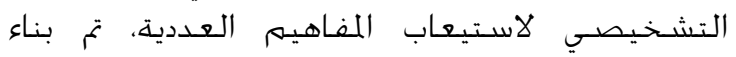

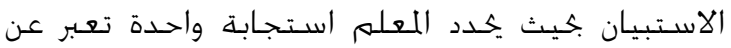

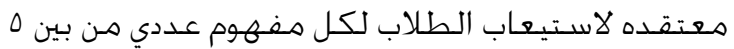

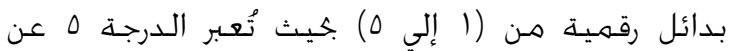

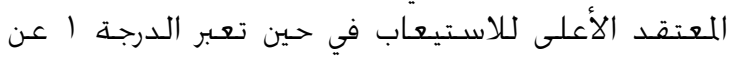

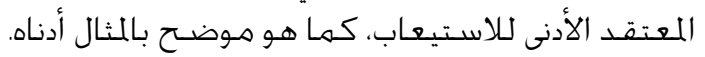

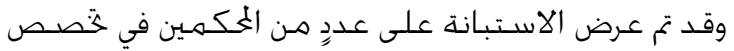

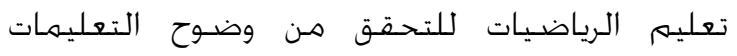

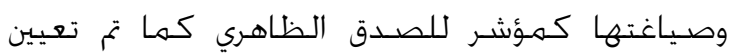

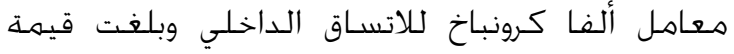

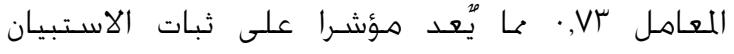

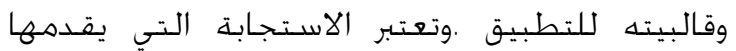

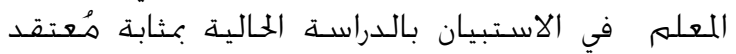

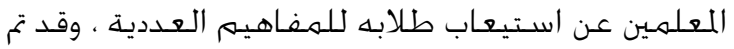

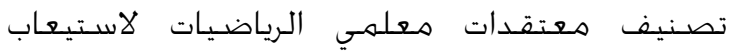
الطلاب كما هو موضحح في جدول ؟مئ.

\section{مرحلة تقنين الاختباز}

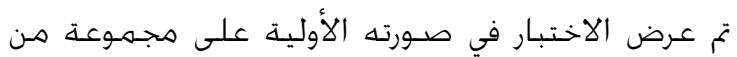

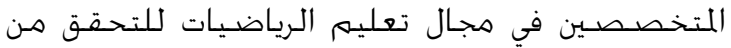

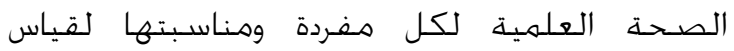

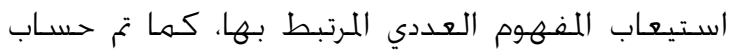

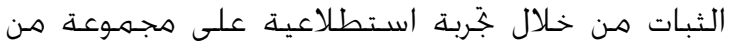

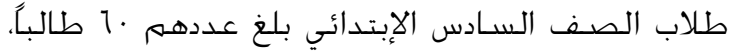

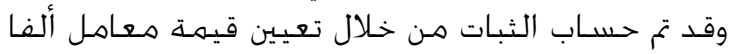

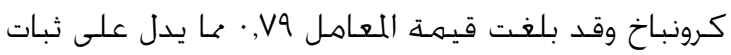

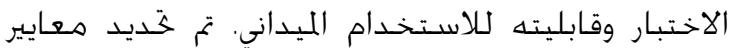

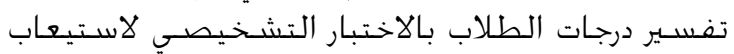

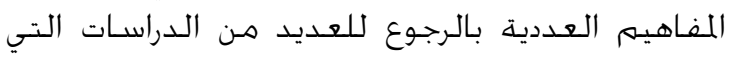
اهتمت بقياس الاستيعاب كالتالي:

معيار الخفاض الاستيعاب: تتباين الدراسـات في

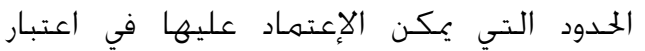

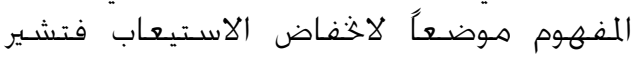

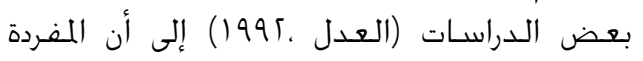
التي يخفق •م\% من الطلاب في الإجابة عليها

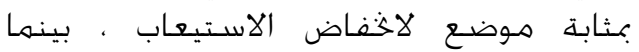

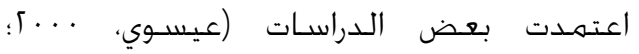

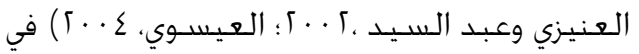
اعتبار المفردة التي يخفق ·عها من من الطلاب في

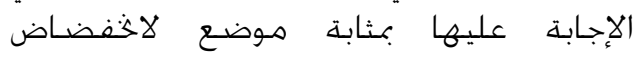

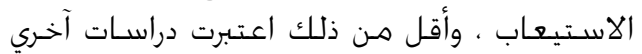

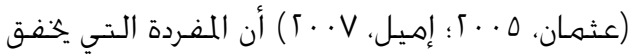

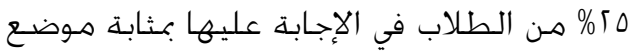

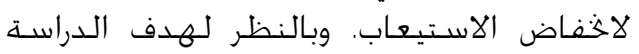

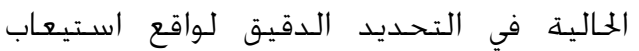

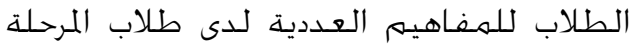

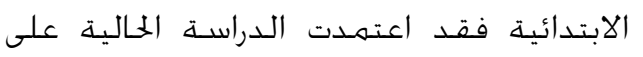

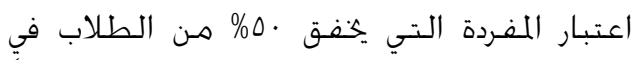
الإجاباة عليها بالاختبار التشخيصي التهي يمثل معياراً

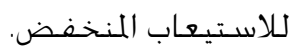

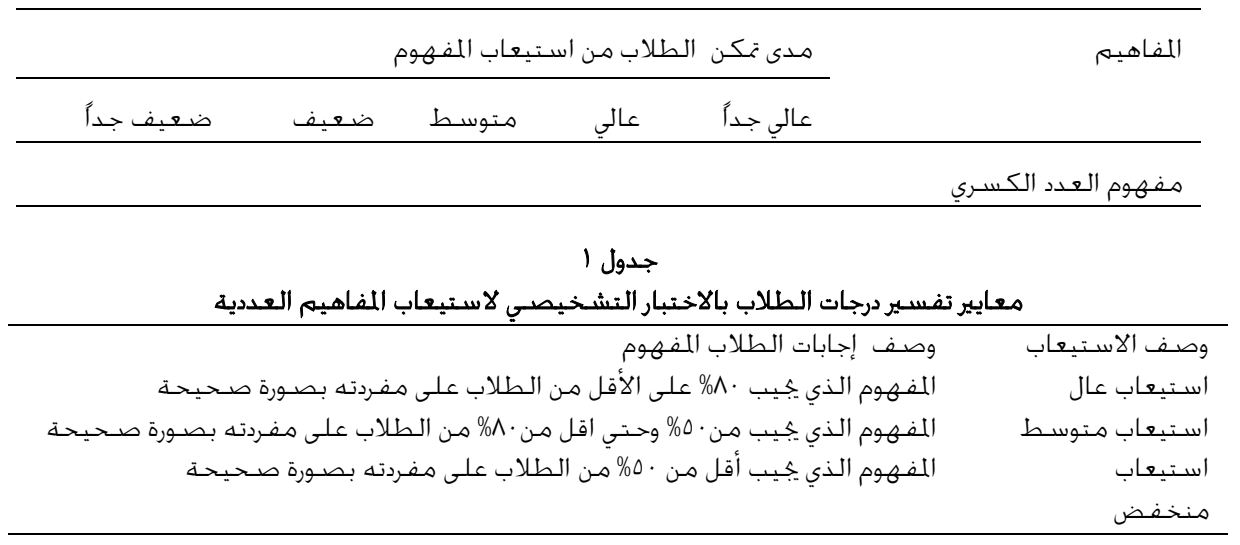


جدول

معتقدات المعلمين خو اسبتعاب الطلاب للمفاهيم العددية العية

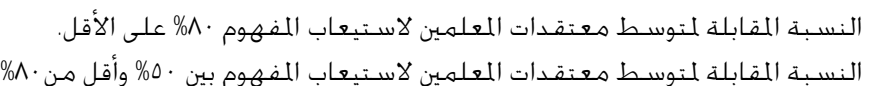

النسـبة المقابلة لمتوسـط معتقدات العلمين لاستيعاب المفهوم أقل من ه \% .
وصف معتقدات المعلمين

استيعاب عال معال

استيعاب متوسط عابط

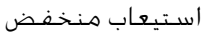

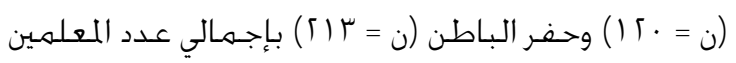

\section{نتائج الدراسـة}

تتناول الجـئيـة التالية نتائج الدراســـ مـن خـال الإجـابة

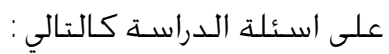
أولاً: ما مدى استيعاب طلاب المرحلة الابتدائية بالمملكة

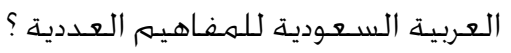

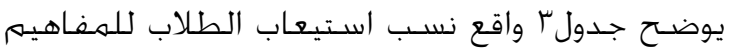

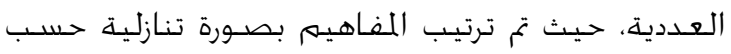

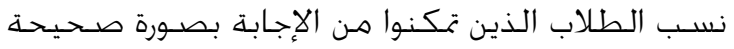

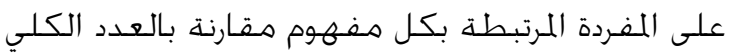

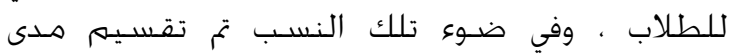
اسـتيعاب الطلاب للمفاهيم العددية لثلاثة فئات:

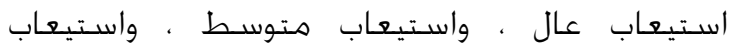

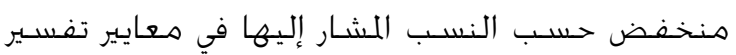

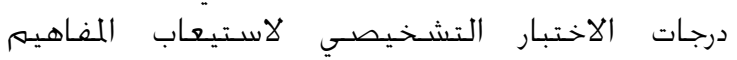
العدديـة.

ويتضح من جـدول ץ أن نسبة اللفـاهيم التي يستوعبها

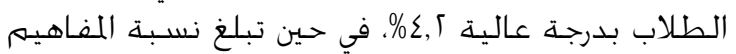

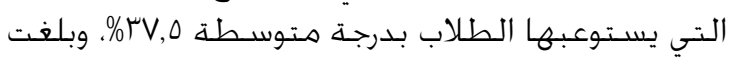

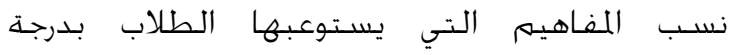

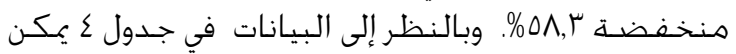

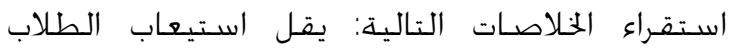

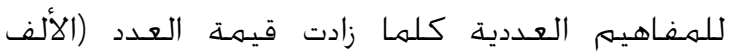
والمليون واللليار).

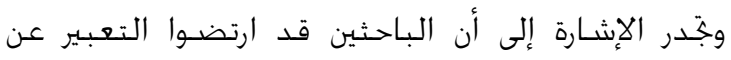

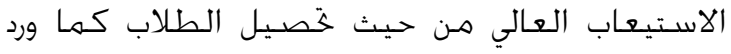

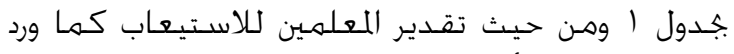

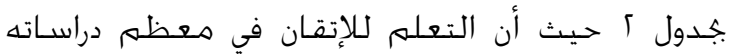

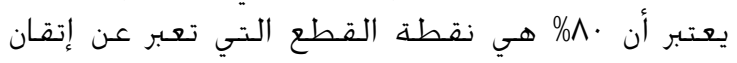
التعلملم.

\section{تطبيق أدوات الدراســـ}

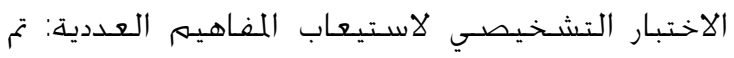

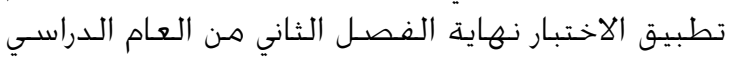

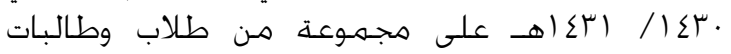

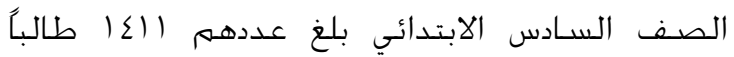

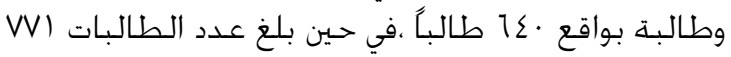

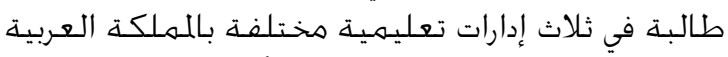

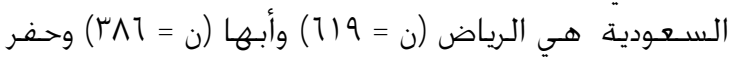

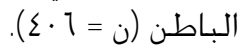

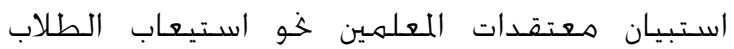

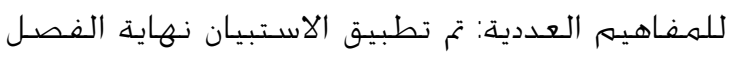

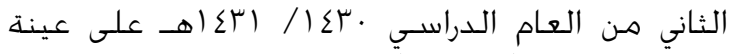

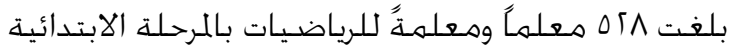

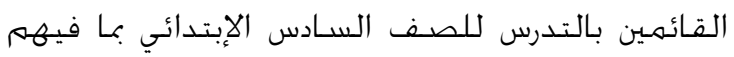

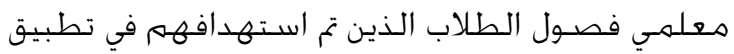

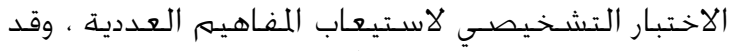

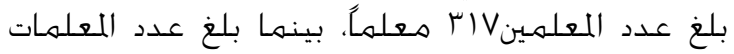

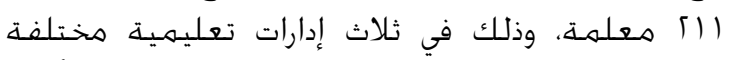
بالمملكة العربية السـعودية هي: الرياض (ن = 90 (1) وأبها فيها

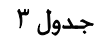

نتائج تطبيق الاختبار التشخيصي لاستبعاب المفاهيم العددية

\begin{tabular}{|c|c|c|c|c|c|c|c|}
\hline مســـــــاب & بشكل صـابة & المفهوم & p & مستـوى الاستيعاب & بشكل صـابة & المفهوم & e \\
\hline منخفضض & $\%$ \%. & العدد الأولى & 14 & عال & $\%$ & العدد ألف & 1 \\
\hline منخفض & ו & مـزلة الجزء العشـري & $1 \varepsilon$ & متوسـط & $9 / N 9$ & العدد الزوجي & 个 \\
\hline منخفض & $\%$ & العـدد الكسـرى & 10 & متوسـط & $9 \mathrm{Nr}$ & العدد مليون & $r$ \\
\hline منخفضض & $\%$ & القـاسـم المشــرك الأكـبر لعـددين & 17 & متوسـط & 91 & العدد الفـردي & $\varepsilon$ \\
\hline منخفض & \% & النسبة الطبيعية ط & IV & متوسـط & ז ז & قواسـم العدد & 0 \\
\hline منخفضض & \%. & العوامل الأولية للعدد & $1 \wedge$ & متوسـط & $\%$. & مـربع العـدد & 1 \\
\hline منخفضض & $\%$ & اللضـاعفـات المشـتركة لعددين & 19 & متوسط & $\% 09$ & مـزلة رقم في عدد صـيح & $\mathrm{V}$ \\
\hline منخفضض & $\%$ & العـد العشـري & 「. & متوسـط & $\%$ & العدد مليار" & $\wedge$ \\
\hline منخفض & $\% \wedge$ & عوامل العدد & 11 & متوسط & $\% 107$ & القوة الأسـية & 9 \\
\hline منخفض & \% V & مضـاعفات القوة الأسية & it & متوسـط & $\%$. & مضـاعفات العـدد & 1 . \\
\hline منخفضض & $\%$ & القواسـم المشتركة لعـدين & rr & منخفض & $\%(\Sigma 9$ & مكعب العـد & 11 \\
\hline منخفضض & $\% 11$ & الكســر العشــري ـ ـ & $\lceil\varepsilon$ & منخفض & $\% \Sigma \wedge$ & المضـاعف المشــرك الأصــر لعددين & 15 \\
\hline
\end{tabular}


مضاعفات القوى الأسية وينطبق ذلك الك على مفاهيم

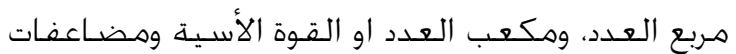

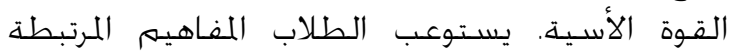

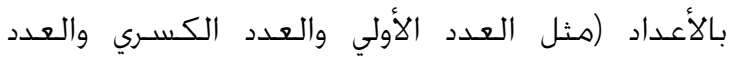

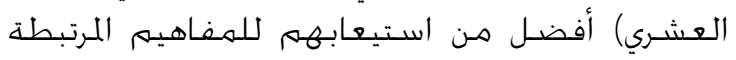

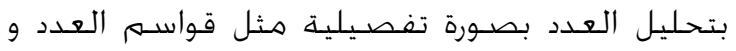

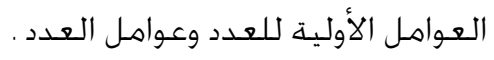

ثانياً: ما واقع معتقدات معلمي الرياضيات المرحلة

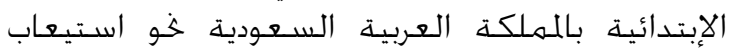

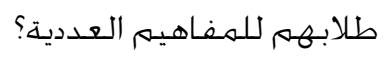

يوضح جدول ع نسب تعبير المعلمين عن معتقداتهم

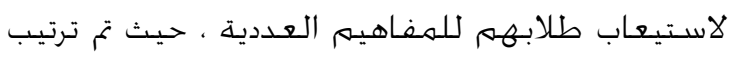

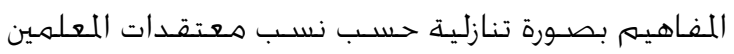

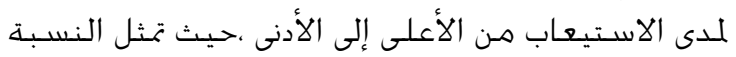

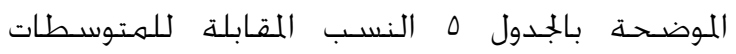

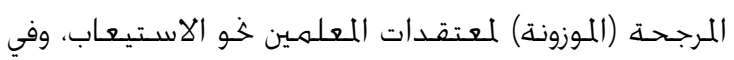

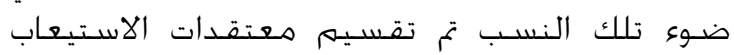

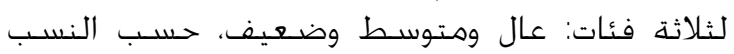

المشار إليها في استبيان معتقدات المعلمين بجدول (؟) ).

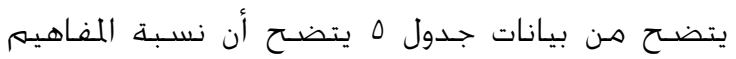

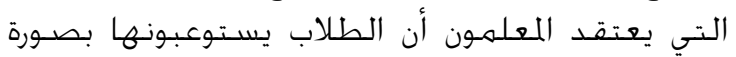

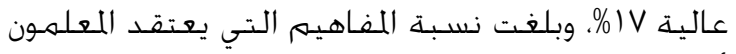

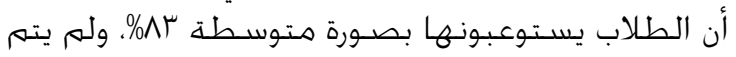

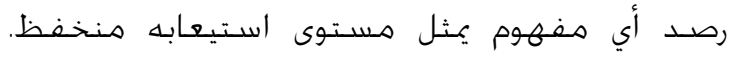

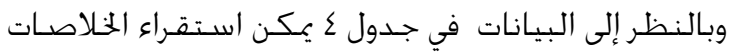

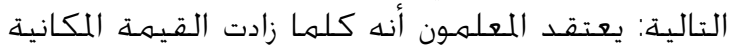

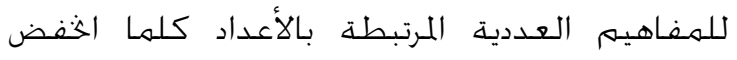

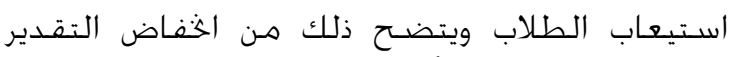
لاستيعاب مفاهيم (الألف والمليون واللميار).

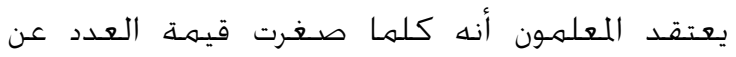

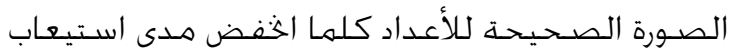

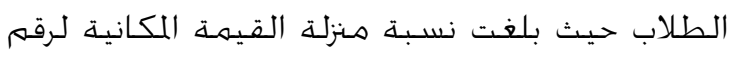

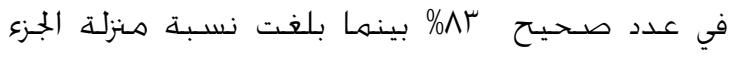

$$
\text { العشـري عا\&. }
$$

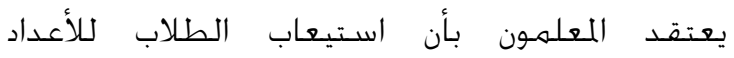

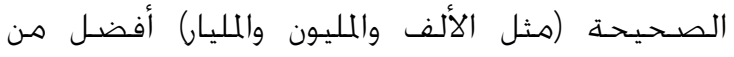

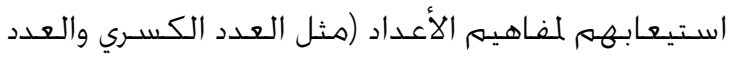

العشـري).

يعتقد المعلمون باستيعاب الطلاب للمفاهيم المرتبطة

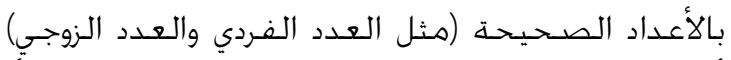

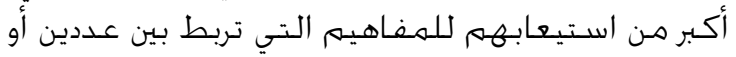

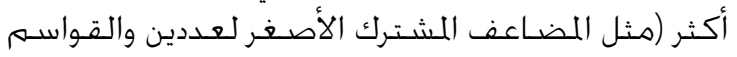

المشتركة لعددين والقاسـم المشتـرك الأكبر لعددين).
جدول

نتائج نطبيق استبيان معتقدات المعلمين لاستيعاب طلابهم

\begin{tabular}{|c|c|c|c|c|}
\hline الاستيعاب معتقد & 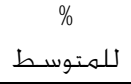 & المتوسط المام & المتغير & e \\
\hline عال & $\%$ & $\varepsilon, r$ & العـد الفـردي & r \\
\hline عال & $\% \Sigma$ & $\varepsilon, \Gamma$ & العدد ألف " & r \\
\hline عال & $\%$ & $\varepsilon, 1$ & مـنزلة رقم في عدد & $\varepsilon$ \\
\hline متوسـط & $9 / N 9$ & $\varepsilon, \cdot$ & صربع العديح & 0 \\
\hline متوسـط & $9 / N 9$ & $\varepsilon$, & مضـاعفـات العـدد & 1 \\
\hline متوسـط & $9 N 9$ & $r, 9$ & العـد مليون & V \\
\hline متوسـط & $9 \mathrm{NV}$ & $r, \Lambda$ & العـدد مليار & $\wedge$ \\
\hline متوسـط & $9 \mathrm{NV}$ & $r, \Lambda$ & العـد الكســري & 9 \\
\hline متوسط & $9 \mathrm{N1}$ & $r, \Lambda$ & العـد الأولي & 1. \\
\hline متوسـط & $9 \mathrm{N1}$ & 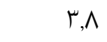 & مكعب العدد & 11 \\
\hline متوسـط & शNo & $r, \mathrm{~V}$ & العدد العشـري & 15 \\
\hline متوسـط & $\$ N \Sigma$ & $r, \mathrm{~V}$ & الكســر العشـري & $1 \%$ \\
\hline متوسـط & $9 \mathbb{N}$ & $r, \mathrm{~V}$ & القوة الأسـية " & $1 \varepsilon$ \\
\hline متوسـط & $9 \pi$ & $r, \mathrm{~V}$ & مـنزلة الجزء العشـري & 10 \\
\hline متوسط & $9 \mathrm{Nr}$ & $r, \mathrm{~V}$ & المضاعفات المشتركتة & 17 \\
\hline & & & لعددين & \\
\hline متوسـط & $9 N 1$ & $r, 1$ & قواسـم العدد & IV \\
\hline متوسـط & $9 N$ & $r, 0$ & العوامل الأولية للعدد & 11 \\
\hline متوسـط & N & $r, 0$ & عواهل العدد & 19 \\
\hline متوسـط & $\mathbb{N}$ & r,o & الأضضـاعف لعددين المشترك & $\Gamma \cdot$ \\
\hline متوسط & $\% 179$ & $r, 0$ & لعددين القـم المشتركة & $\lceil 1$ \\
\hline متوسط & $\% / 79$ & $r, 0$ & القـاسـم المشـرك الأكـبر & it \\
\hline متوسط & $\% 179$ & $r, r$ & لعضداعفن القوة & $i r$ \\
\hline متوسط & $\% / 79$ & $r, r$ & النسبة الطبيعية ط & $\lceil\varepsilon$ \\
\hline
\end{tabular}
للمفاهيم العددية

يستوعب الطلاب المفاهيم العددية المرتبطة بالقيم

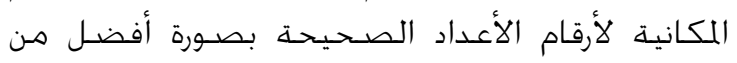

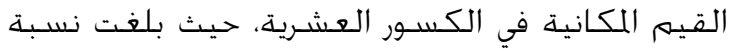

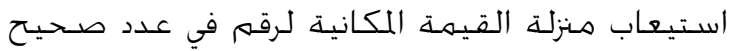

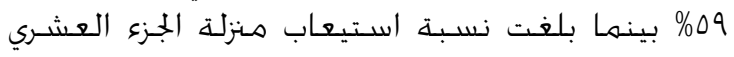

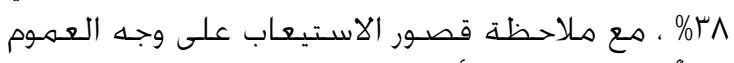

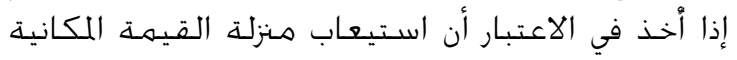

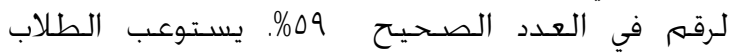

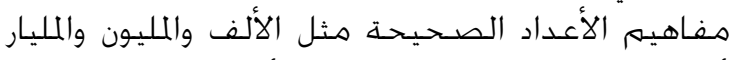

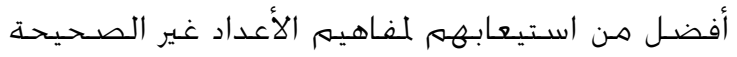

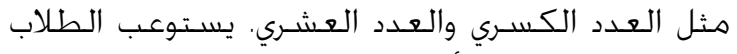

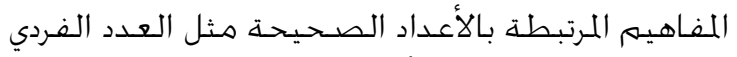

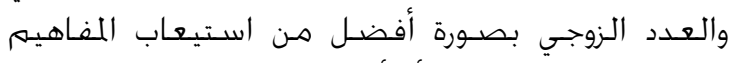

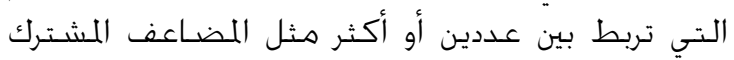

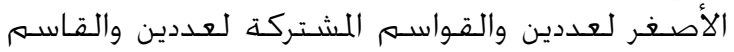

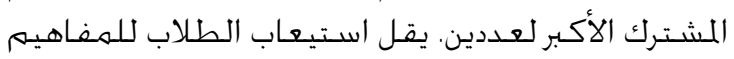

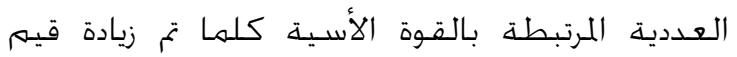


بُعد الاتفاق: رغم ما أشـار إليه البعد السـابق من تباينات

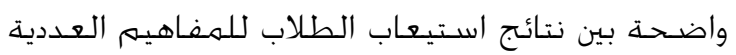

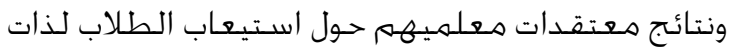

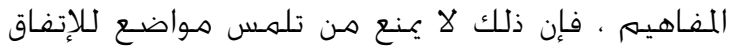

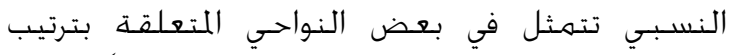

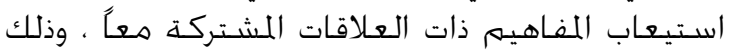

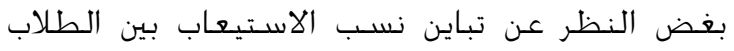

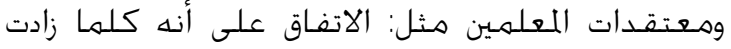
القيمة المكانية للمفاهيم العددية المرتبطة المانية الأعداد الماد المات

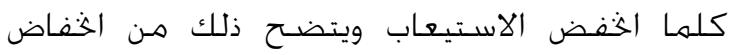

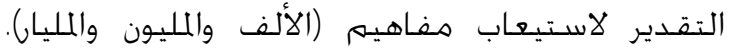

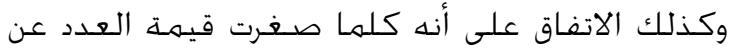

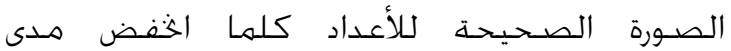

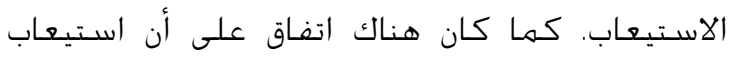

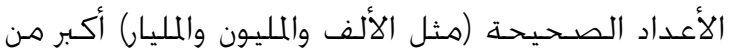

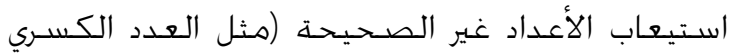

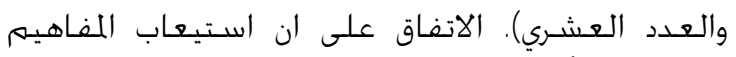

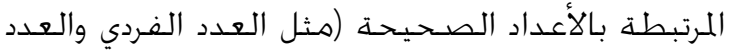

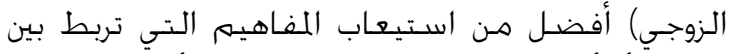

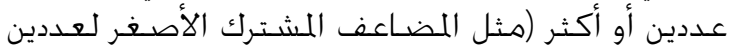

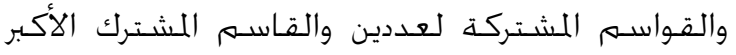

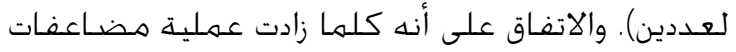

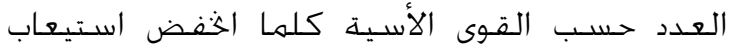

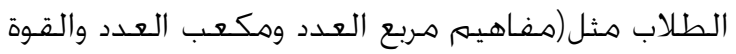

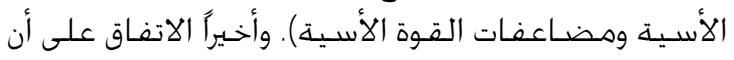

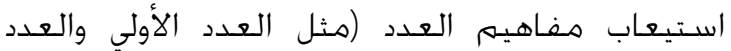

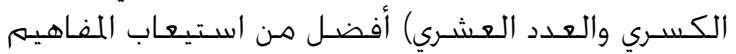

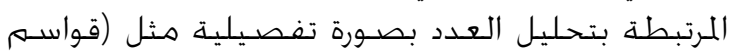
العدد و العواهل الأولية للعدد و عوامل العدد).

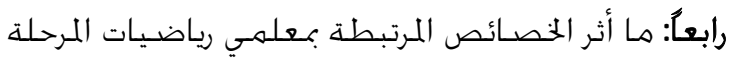

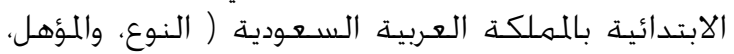

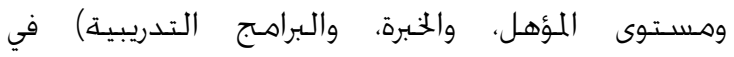
معتقداتهم خو استيعاب طلابهم للمفاهيم العددية؟

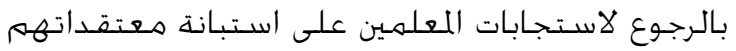

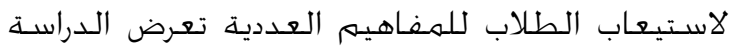

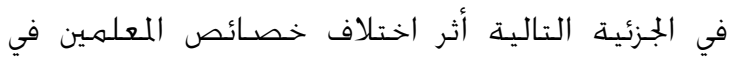
تشكيل معتقداتهم لاستيعاب طلابهم للمفاهيه الماتهم

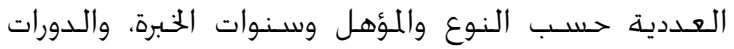
التدريبية، والإدارة التعليمية.

أثر النوع: تم استخـام نتائج اختبار t-test للمقارنة بين

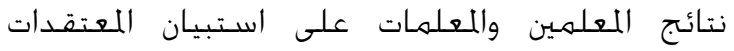
لاستيعاب المفاهيم العددية وكانت النتائج كما في العان العان

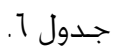

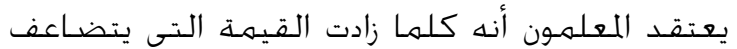

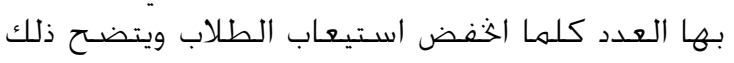

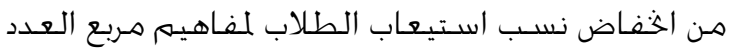
ومكعب العدد والقوة الأسية ومضاعفات القوة الأسـية. يعتقد المعلمون بأن استيعاب الطلاب لففاهيم العدد العداب

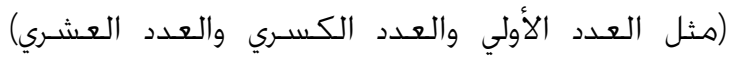

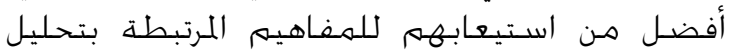
العدد بصـورة تفصيلية مثل (قواسـم العدد و العواهل المرتطيل الأولية للعدد و عوامل العدد ). تتسـم معتقدات المعلمين بنوع من الاتساق على وجهـ لاونه

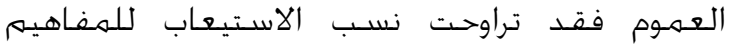

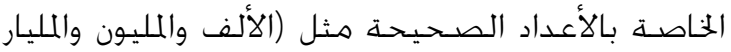

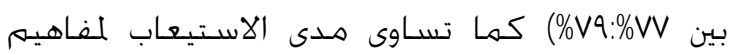

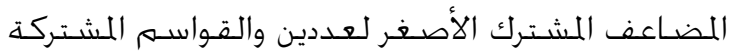

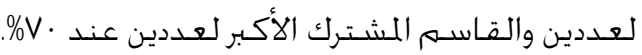
ثالثا: ما وجه التباين والاتفاق بين استيعاب طلاب المرحلة

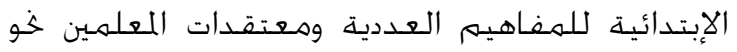

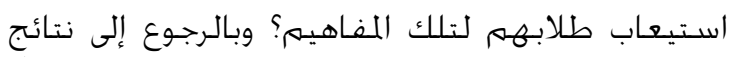

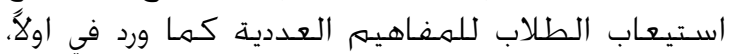

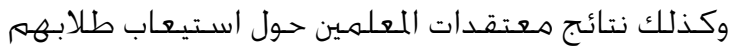
لذات المفاهيم يمكن استخلاص بعدين للتباين والاتفاق: بُعد التباين: يوجد تباين واضسح بشكل عام بين نتائج

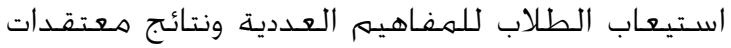

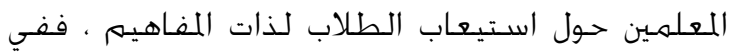

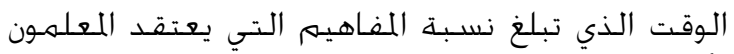

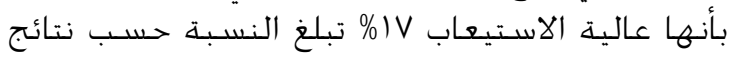

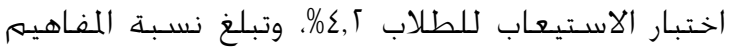

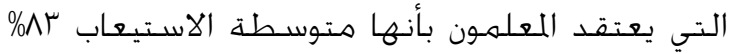

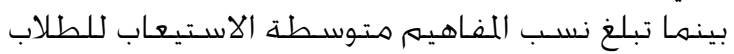

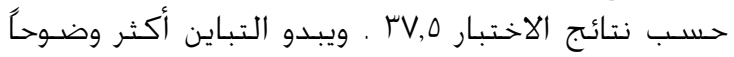

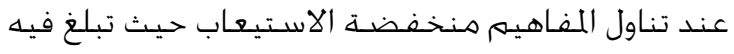
نسبة المفاهيم التي يعتقد المعلمون انه لا لا يوجد العابه

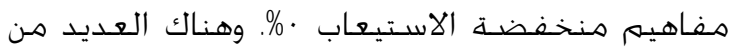

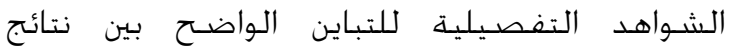

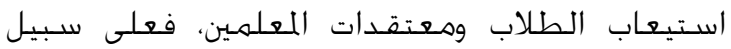

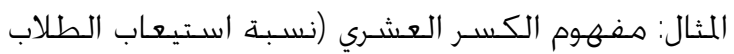

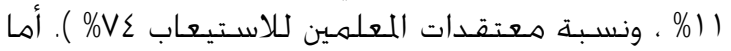

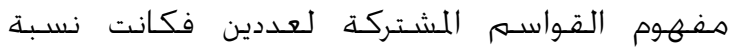

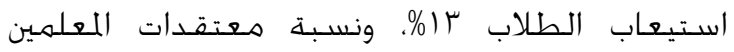

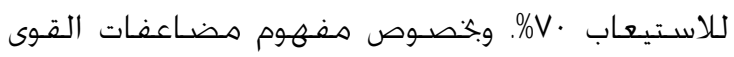

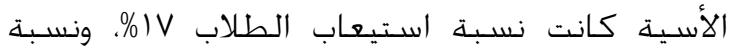

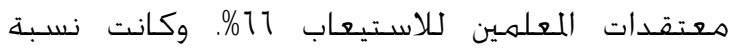

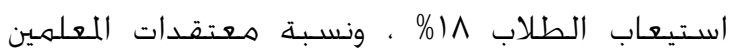
للاستيعاب (/\%\% لمفهوم عوامل العدد. 


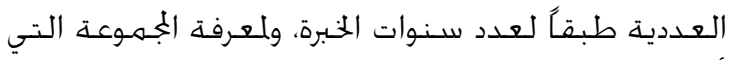

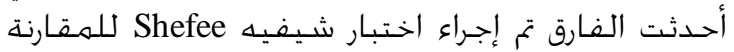

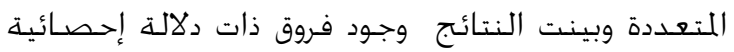

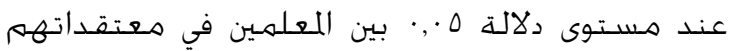

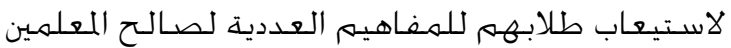

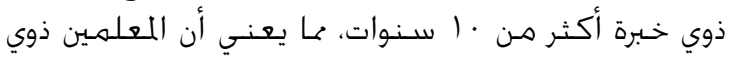

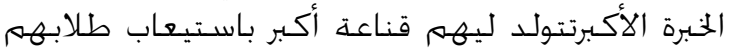

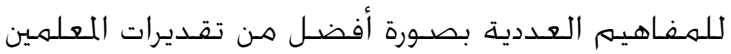

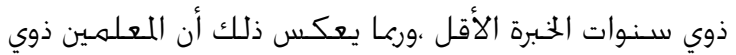

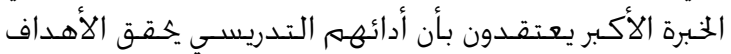

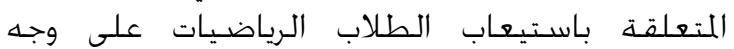

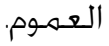

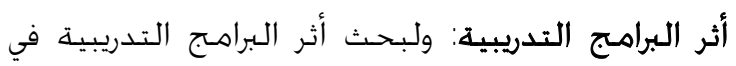

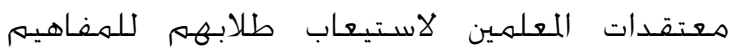

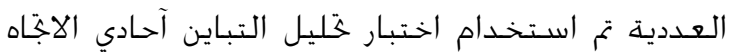

فكانت النتائج كما يوضـح جـدول 9.

\section{جدول 9}

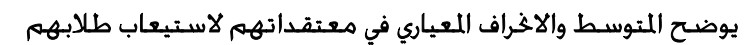

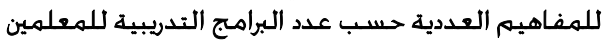

\begin{tabular}{|c|c|c|c|c|}
\hline الدلالة & فيمة & اللعياري & المتوسـط & الدورات التدريبية \\
\hline \multirow{3}{*}{ غإِصير دائيًا } & \multirow{3}{*}{$\Gamma, \Lambda \uparrow 9$} & $\cdot, \mathrm{V} 7 \mathrm{~T}$ & $r, \mathrm{Vq}$ & أقل من ؟ دورات (ن=؟ · ا \\
\hline & & $\cdot, 100$ & $r, q \wedge$ & من r - -ه دورات (ن= | · ؟ \\
\hline & & $\cdot, \wedge \vee q$ & $r, \Lambda r$ & أكثر من ه دورات (ن= ع ؟؟ \\
\hline
\end{tabular}

يتضـح من جـدول 9 أنه لا توجـد فـروق ذات دلالة إحصـائية

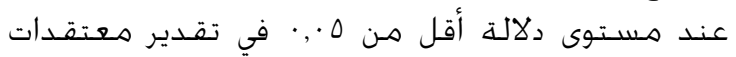

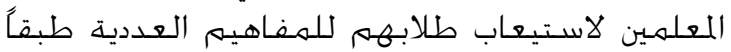

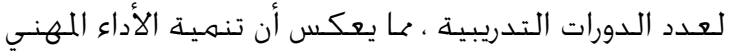

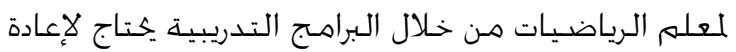

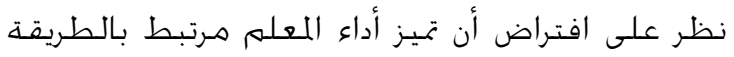

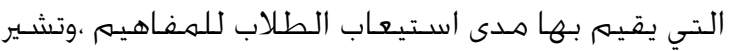

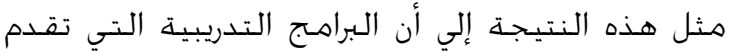

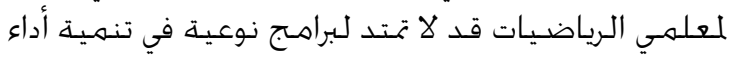

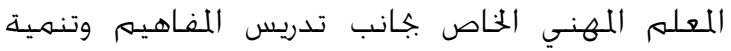

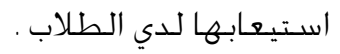

\section{المناقشـــ}

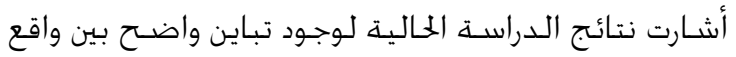

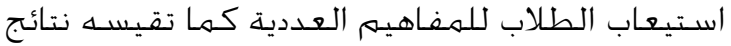

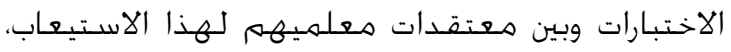

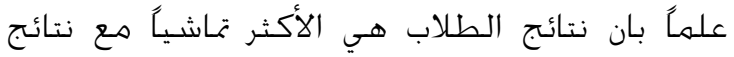

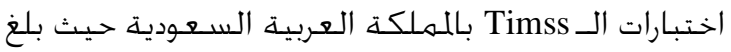

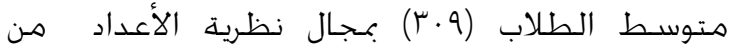

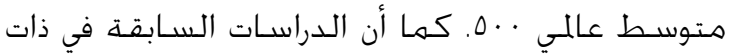

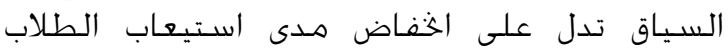

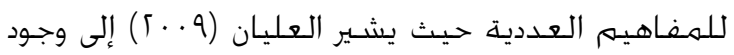

\begin{tabular}{|c|c|c|c|c|c|}
\hline \multicolumn{6}{|c|}{ 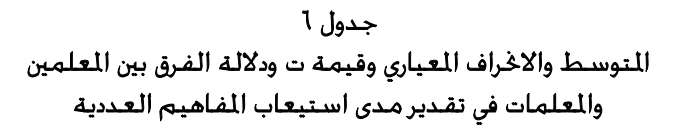 } \\
\hline \multirow[t]{2}{*}{ الدلالة } & قيمة & الاخخراف & المتوسـط & العدد & النوع \\
\hline & ت & المعياري & & & \\
\hline \multirow[t]{2}{*}{$\cdot, \cdot 1$} & $0, \mathrm{~V})$. & $\cdot, \wedge \mu$. & $r, \mathrm{VT}$ & r11 & معلمون \\
\hline & & · & $\sum, 11$ & Г1) & معلمات \\
\hline
\end{tabular}

يتضـح من جـول 1 وجود فروق ذات دلالة إحصـائية بين

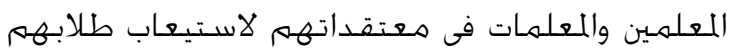

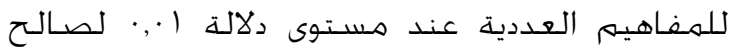

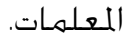

أثر المؤهل: تم استخــام اختبار t-test للمقارنة بين

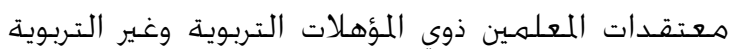
لمدى استيعاب الطلاب للمفـاهيم العددية.

جدول

يوضح الفروق بين المعلمين في تقدير مدى استيعاب المفاهيم

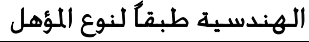

\begin{tabular}{|c|c|c|c|c|c|}
\hline \multirow[t]{2}{*}{ الدلالة } & قيمة & الاخراف & المتوسـط & العـد & النوع \\
\hline & ت & المعياري & & & \\
\hline \multirow[t]{2}{*}{$\cdot, \cdot 1$} & $\varepsilon, \wedge \Sigma 9$ & $\cdot, \mathrm{V} \mu \varepsilon$ & $r, 95$ & $\sum \Lambda \Lambda$ & تربوي \\
\hline & & $1, \cdot \Lambda$. & $r, \mu)$ & ra & غير تربوي \\
\hline
\end{tabular}

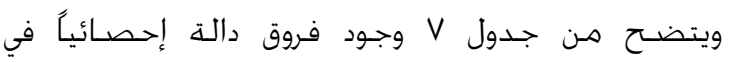

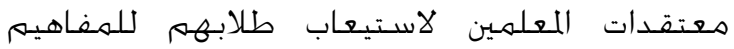

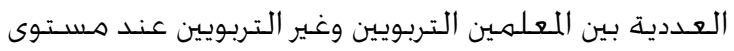

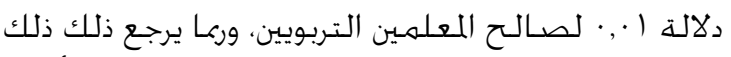

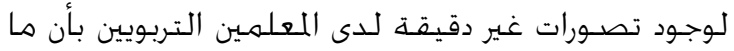

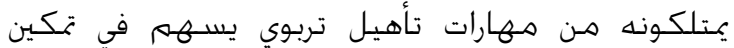

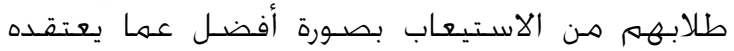
المعلمسين غير التربويين.

أثر سـنوات الخبرة: لبحـث أثر عدد سـنـوات خـبرة المعلميـين :

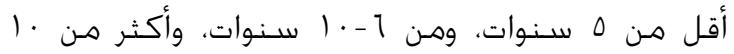

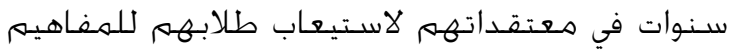

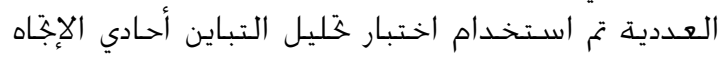

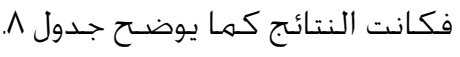

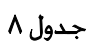

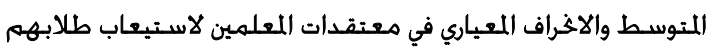

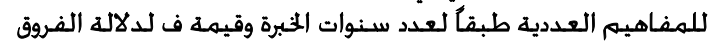

\begin{tabular}{|c|c|c|c|}
\hline قيمة ف & الالعخراف & المتوسـط & الخبرة \\
\hline \multirow{3}{*}{$* r, q \mu$. } & $\cdot, 1 \sum \mu$ & $r, \mathrm{~V} r$ & أُقل من ه ســوات (ن=90) \\
\hline & $\cdot, \mathrm{V} \Delta \wedge$ & $r, \wedge)$ & من 1 -. 1 سـنوات (ن=.r (1) \\
\hline & $\cdot, \wedge 19$ & $r, 97$ & 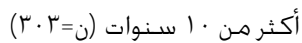 \\
\hline
\end{tabular}

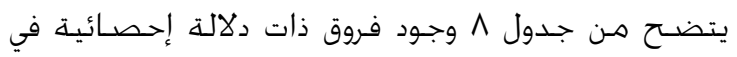

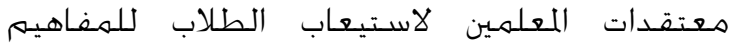


- إعداد براهـج تدريبية وإرشادية متخصصـة

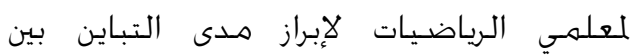

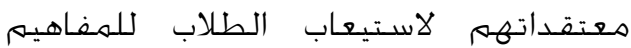

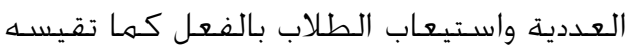

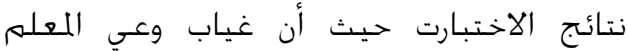

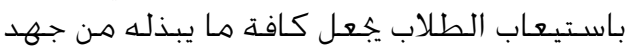

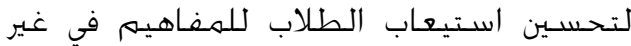
طريقـه الصسيح. الربط بين تقييهمات أداء المعلمـين حسب التقارير

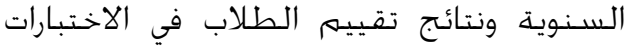

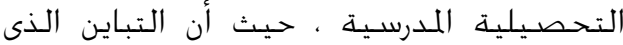

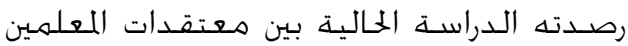

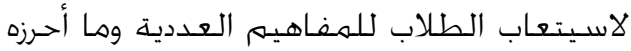
الطلاب هن اسـتيعاب يشير إلي أن واقع نتائج

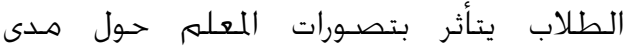

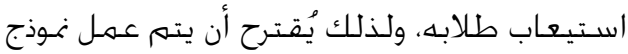

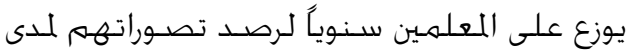

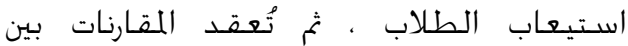

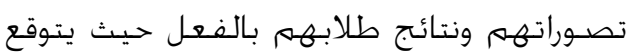

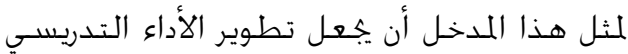

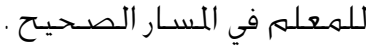

إعادة النظر في الكيفية التي يته بها تقديم

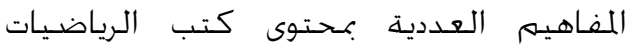

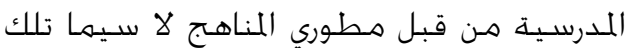

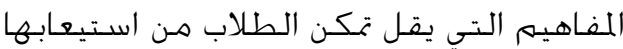

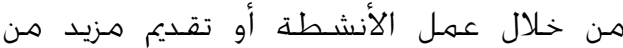
الأمثلة التوضـيــيـة.

إعادة النظر في أدلة معلمي الرياضيات بحيث

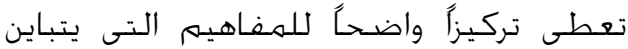

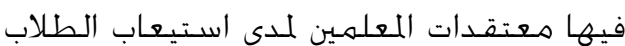

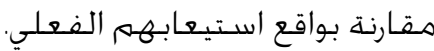

أفرزت نتـائج الدراسـة الحالية أن استيـعاب الطلاب

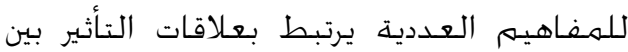

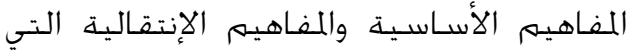

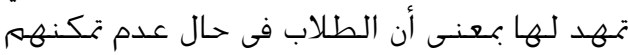

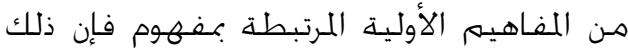

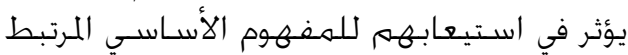

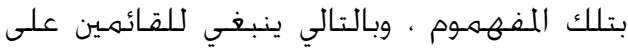

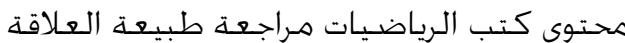

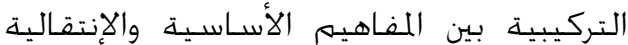

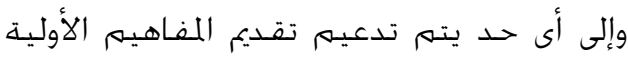

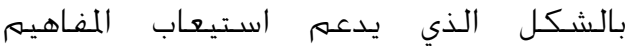

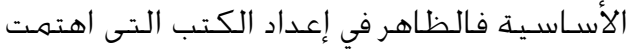

ضعف عام في اللفاهيم الأسـاسية للرياضـيات لدى

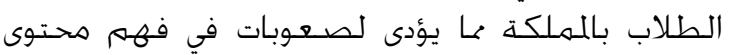
الرياضـيات وارتفاع نسـب الرسـوب. وتوضـح دراســـ مـداح

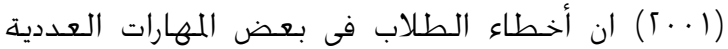
يرجع إلى ضهفهم في اكتسـاب المفاهيم والمهارات

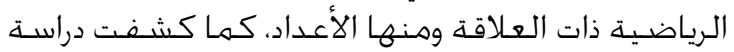

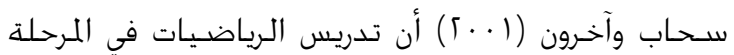

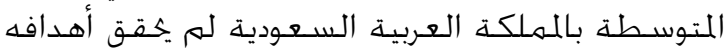

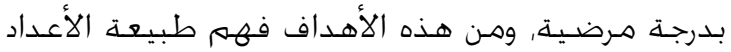

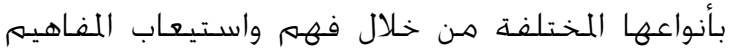

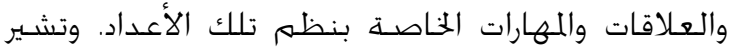

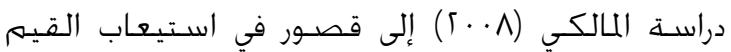

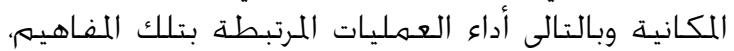

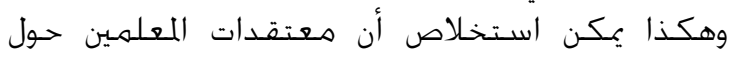

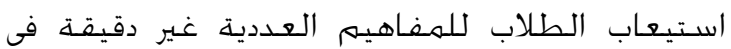

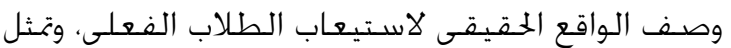

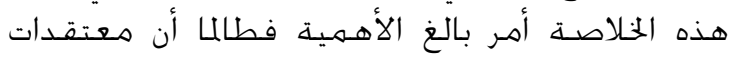

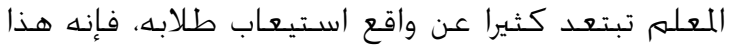

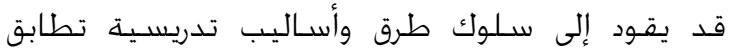

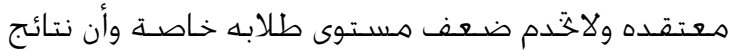

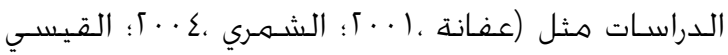

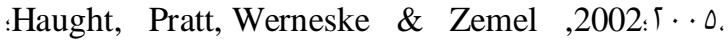

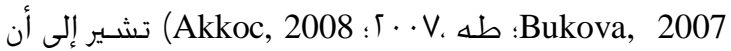

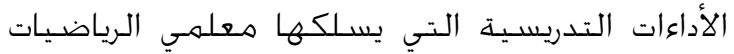

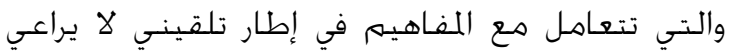

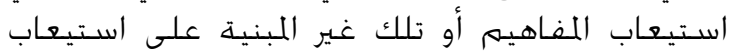

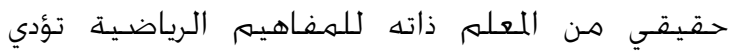

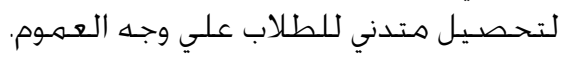
كما يشير ختليل نقاط التبيان والاتفاق بين نتائج

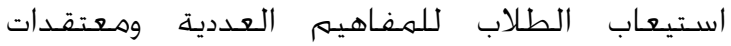

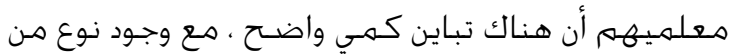

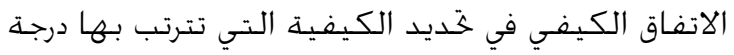

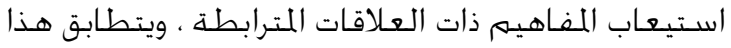
الاستخـلاص مع نتائج دراسـات (Beaudion, 2004 :علي،

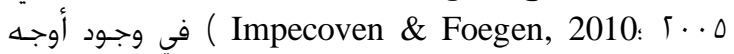

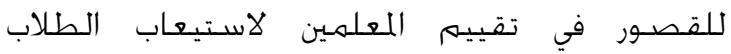

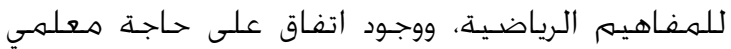

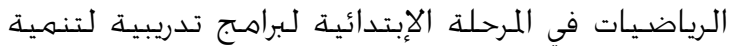

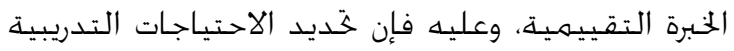

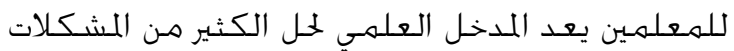

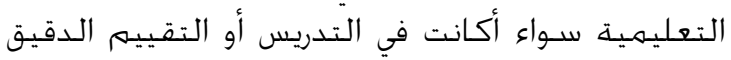
للطلاب.

توصيات الدراسـة: في ضـوء النتائتج التي تم انبثقت عـن

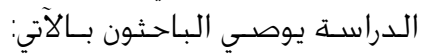


حهزة، محهد (· ( • ؟). مفاهيم أسـاسية في الرياضيات

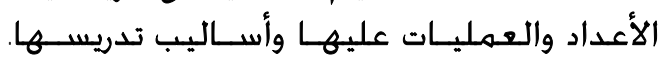
القاهرة: دار الفكر العربي.

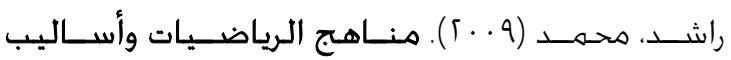
تدريسها للصفوف الرئيسية. عمان: دار الجنادرية.

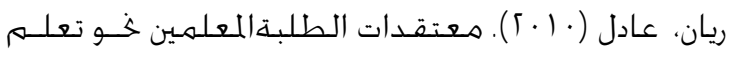

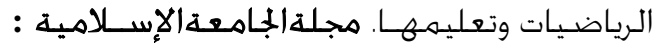

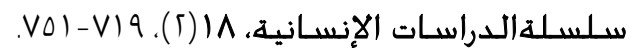

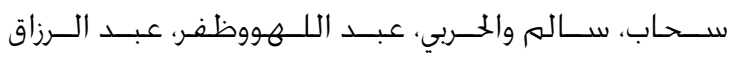

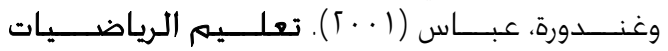

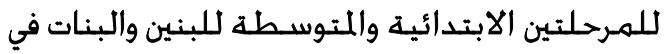
المملكة العربية السعودية. الرياض: مدينـة الملـك فيك عبد العزيز للعلوم والتقنية.

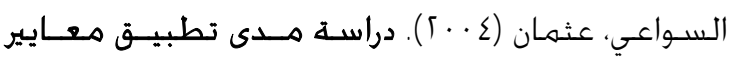

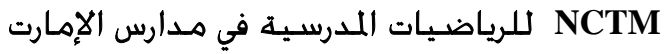

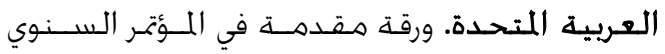

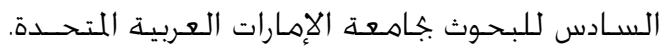
جامعة الإمارات العربية المتحدة.

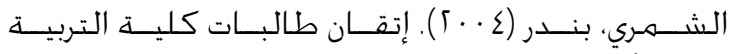

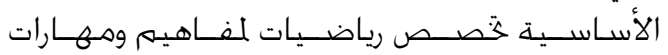

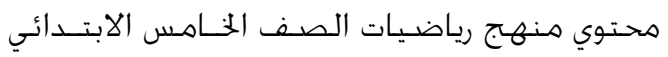

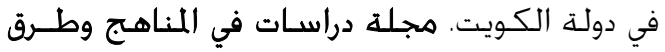

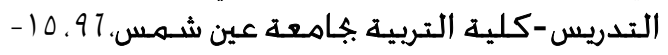

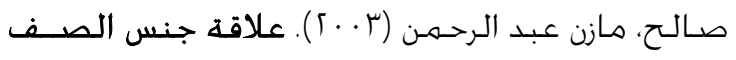

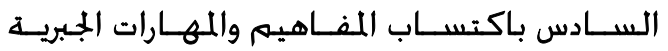

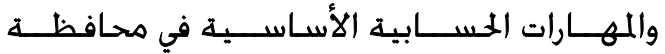

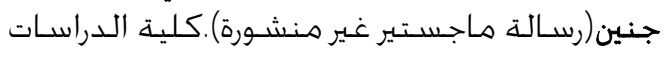
العليا، جامعة النجاح الوطنية، فلسيطين. صديق، محفوظ وزهران، عبد العظيم وعبد الجيد، أسـامة

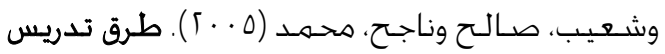

الرياضيات. سـوهاج: مطبعة الجامعة بسـوهاج.

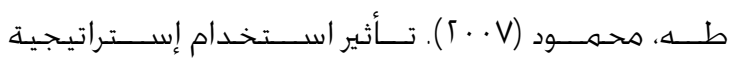

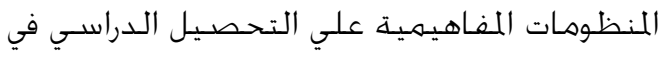

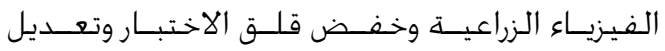

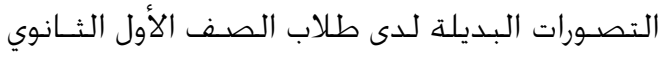

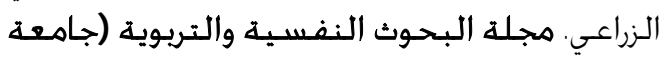

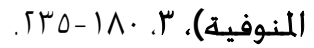

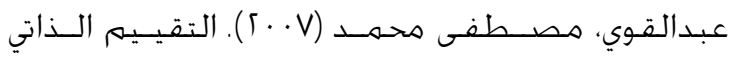

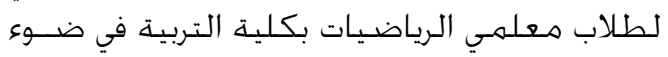

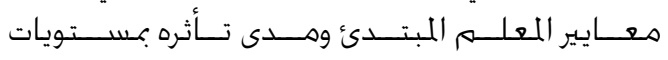

بها الدراسـة الحالية أنها تولي المفاهيم

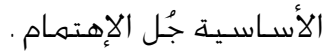

\section{المراجع}

\section{References}

إبراهيم، مجدي ( ( . م). تعليم وتعلم المفاهيم الرياضية للطفل. القاهرة: مكتبة الأجلو المصرية.

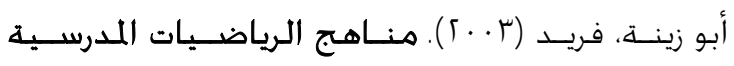

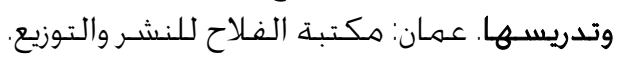

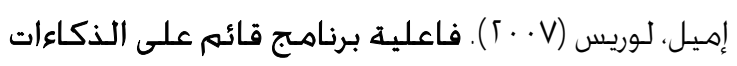

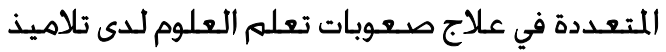
المرحلة الإعدادية (رسـالة دكتوراه غير منشـورة).كلية الماتية التربية بالإسـماعيلية، جامعة قناة السـويس.

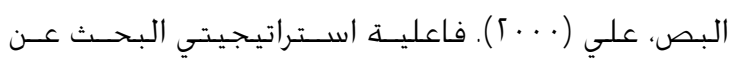

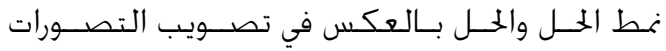
الخطأ لدي طلاب الصـف الثالث الإعـــادي في مهـادة

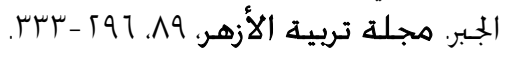

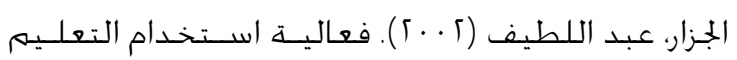

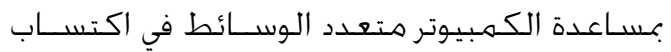

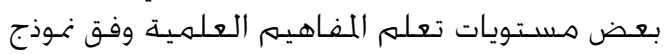

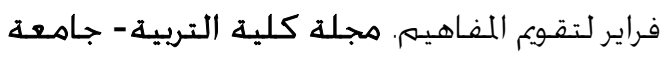

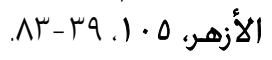

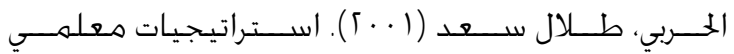

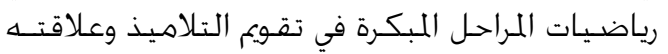

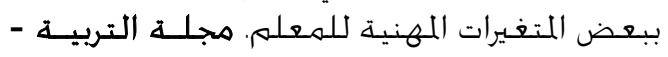

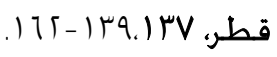
حسانين، على (999 )). فاعلية اسـتخدام التعلم التعاوني

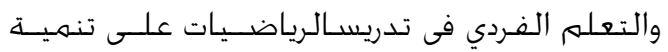

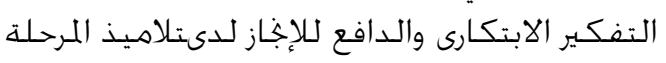

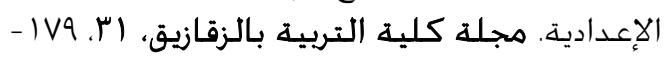
. $1 \leqslant$

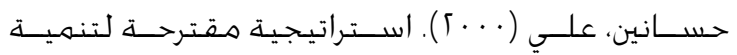

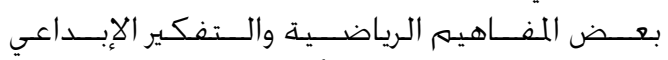

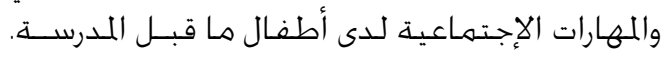

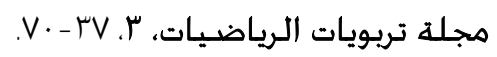

حسين، منى عبد الهادى (999 ()). فاعلية برنامهج مقتــرح

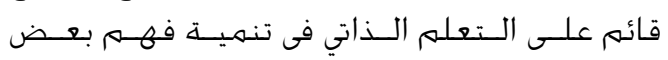

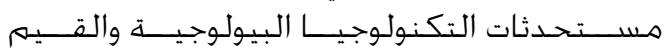

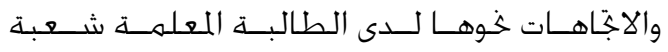

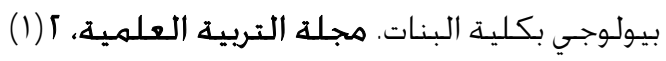
$.111-10 \mathrm{~V}$ 


$$
\begin{aligned}
& \text { المرحلة الإعدادية (رسـالة ماجسـتير غـير منشـــورة). } \\
& \text { معهد الـراسـات التربوية جامعة القـاهرة. }
\end{aligned}
$$

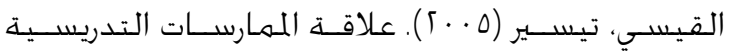

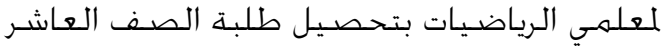

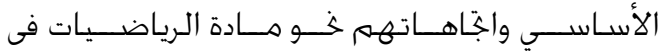

$$
.19-7 \% .09
$$

المالكي، عبد العزيز (^ · · ؟). أثر أنشـطة إثرائية باستخدام

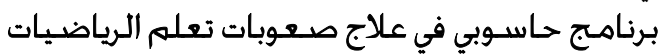

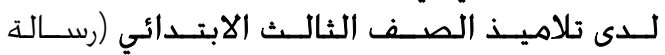

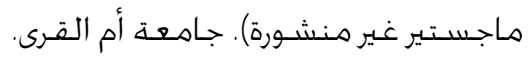

مـداح، سـامية ( ( . ). فاعلية اسـتخـدام التعلم التعاوني

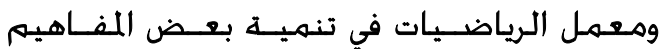

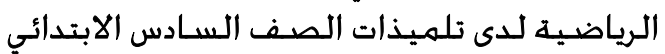

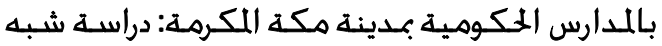

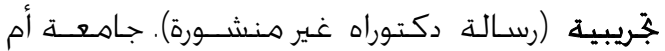
القـرى.

وزارة التربية والتعليهم - السـعودية (·ــ (هـ). دليل المعلم

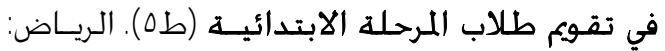
الإدارة العامة للتقويم والجودة التربوية.

Afamasaga, K. (2008). Students' conceptual understanding and critical thinking: a case for concept maps and Venn-diagrams in mathematics problem solving. Australian $M$ athematics Teacher, 64(2), 8-17.

Akkoc, H. (2008). Preservice mathematics teachers' concept images of radian. International Journal of $M$ athematical Education in Science and Technology, 39(7), 857-878.

Barkatsas, A., \& Malone, J. (2005). A typology of mathematics teachers' beliefs about teaching and learning mathematics and instructional practices. $M$ athematics Education Research Journal, 17(2), 6990.

Boggs, S., Shore, M., \& Shore, J. (2004). Using elearning platforms for mastery learning in developmental mathematics courses. $M$ athematics and Computer Education, 38(2), 213-220.

Bukova, E. (2007). The effect of a constructivist learning environment on the limit concept among mathematics student teacher. Educational Sciences: Theory and Practice, 7(3), 1189-1195.

Cheah, L. (2009). Teacher beliefs and the teaching of mathematics and science in english. English Language Journal, 3, 83-101.

Fleener, M. (1996). Scientific world building on the edge of chaos: High school students beliefs about mathematics and science. School Science and M athematics, 6, 312- 320.

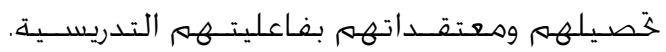

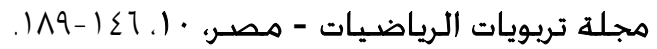

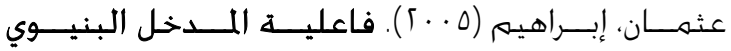

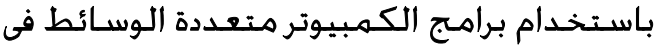

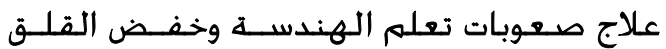

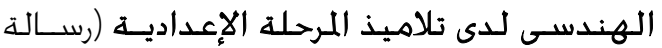

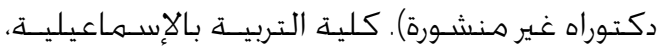

جامعـة قـناة السـويس.

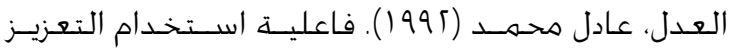

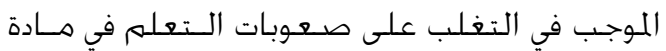

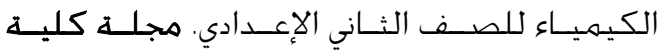

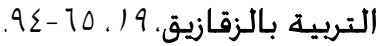

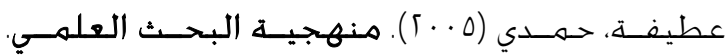
القـاهرة: دار النشـر للجهامعات.

عفانة، عزو (( . . ؟). العلاقة التبادلية بين المعرفة

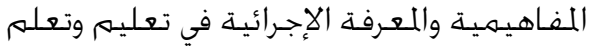

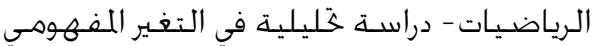

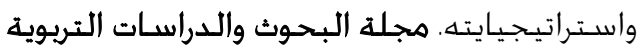

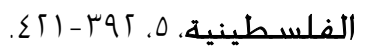

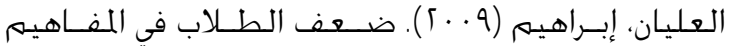

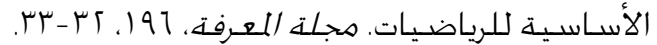

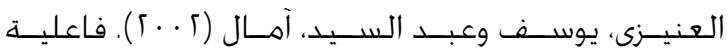

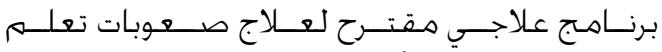

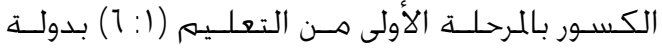

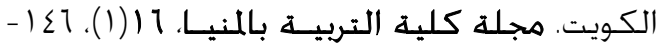

.) 10

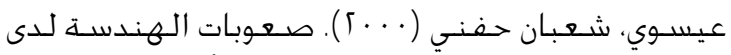

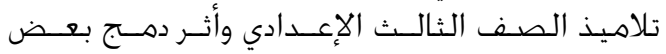

مـداخل التدريس لعـلاجها. مجلة كلية التربية بالمنيا. . . .9- 1 $29 .(1)<$

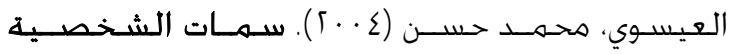

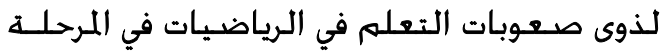

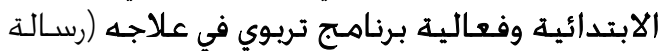

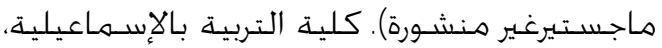
جاهـعة قناة السـويس.

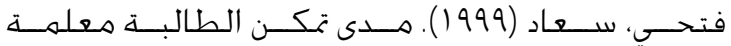

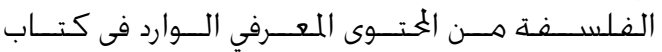

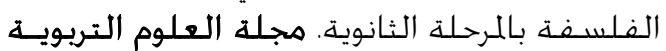

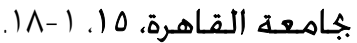

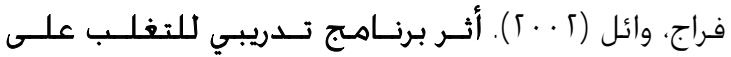

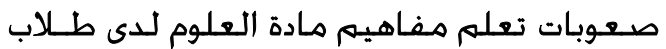


Adams, B. (1975). The family. New York: The Free Press.

Archer, S, L. (1980). Ego identity development among $6^{\text {th }}$, ${ }^{\text {th }}, 10^{\text {th }}, 12^{\text {th }}$ Graders. Dissertation Abstracts International, 41 (3), 1131-1147.

Bosma, H, A., \&Vleioras, G. (2005). Are identity styles important for psychological well being? Journal of A dolescence, 28, 397-409.

Gitanjali, S. (2000). Educational decision making in Asian Indian women: A study on identity development (Unpublished Doctoral Dissertation). University of N orth Carilina.

Gunri, O. Sunil, Z., \& Yidirim, A. (1999). Sources of self-identity among Turkish adolescents. A dolescence, 34 (135), 535.

Hanch, F. (1994). Styles of Identity Formation in Early and Middle Adolescence. Genetic, Social General Psychology M onographs, 120 (4), 435 - 468.

Hollist, D. (2006). Family conflict, negative, emotion, personal and social resources, and delinquency. A merican society of criminology. Annual Meeting, Chicago. USA.

Impecoven, S., \& Foegen, A. (2010). Teaching algebra to students with learning disabilities. Intervention in School and Clinic, 46(1), 31-37.

Kidwill, J., Dunham, R., Bacho, R.,Pastorino, E., \& Potes, P. (1995). Adolescent identity exploration: A test of Erickson's theory of transitional crisis. A dolescence, 30 (120), 785-793.

Levin, T., \& Wadmany, R. (2006). Teachers' beliefs and practice in technology-based classrooms: A developmental view. Journal of Research on Technology in Education, 39(2), 157-181.

Li, Q. (1999). Teachers' beliefs and gender differences in mathematics: A review. Educational Research, 41(1), 63-76.

Liu, P., \& Situ, Y.(2006). The impact of family environment on juvenile delinquency in China and USA. Conference papers: American Society of Criminology, 2006 A nnual Meeting, p. 1. 2.

Meeus, W., \& Dekovic, M. (1995). Identity development parental and peer support in adolescence: Result of a National Dutch Survey. A dolescence, 30 (120), 930-944.

Morgan,P.,Farkas, G., \& Wu, Q. (2009). Five-year growth trajectories of kindergarten. Journal of Learning Disabilities, 42(4), 306-321.

Norland, S., Shover, N., Thornton, W., \& James, J. (2009). Intra-family conflict and delinquency. Pacific Sociological review, 22 (2), 223-240.

Olson, E, T. (2009). Self personal identity. UK: University of Sheffield, Sheffield.

Picciotto, M. (1987). Ego identity development of early adolescence. Dissertation Abstravts, International, 48 (12), 3704-3720.
Protinsky, C. (1988). A Study examining differences between behavioral problems adolescents and their normal peers. Journal of Sport Behavior, 12, 6173.

Quillen, M. (2004). Relationships among prospective elementary beliefs about mathematics, mathematics content knowledge, and previous mathematics course experiences (Unpublished Doctoral Dissertation). Virginia Polytechnic Institute and State University, Virginia.

Raghubar, K., Cirino, P., Barnes, M., Ewing-Cobbs, L., Fletcher, J., \& Fuchs, L. (2009). Errors in multidigit arithmetic and behavioral inattention in children with math difficulties. Journal of Learning Disabilities, 42(4), 356-371.

Rickard, A. (2010). Beliefs and practice aligned with reform: A sixth-grade teacher's response to a student's conjecture about measuring area. National Forum of Applied Educational Research Journal, 23(3), 1-6.

Sahin, C., Bullock, K., \& Stables, A. (2002). Teachers' beliefs and practice in relation to their beliefs about questioning at key stage 2. Educational Studies, 28(4), 371-384.

Santrock, J. (1998). Child development (8th Ed.).USA: McGraw-Hill Companies.

Schwart, S., \& Dunham, R. (2000). Identity status formula: Generating Continues measures of the identity status from measures of exploration and commitment. A dolescence, 35 (137), 147-166.

Shahvarani, A., \& Savizi, B. (2007). Analyzing some Iranian-high school teachers' beliefs on mathematics, mathematics learning and mathematics teaching. Journal of Environmental \& science Education, 2(2), 54-59.

Speer, N. (2005). Issues of mathematics and theory in the study of mathematics teachers' professed and attributed beliefs. Educational Studies in M athematics, 58, 361-391.

Turnuklu, E., \& Yesildere, S. (2007). The pedagogical knowledge inmathematics: Preservice primary mathematics teachers' perspectives in Turkey. Retrieved 1 January 2011, www.k12prep.math.ttu.edu.

Yildiran, G., \& Aydin, E. (2005). The effects of mastery learning and cooperative, competitive and individualistic learning environment organizations on achievement and attitudes in mathematics. Research in $M$ athematical Education, 9(1), 55-72.

Zimmerman, B., \& Dibenedetto, M. (2008). Mastery learning and assessment: implications for students and teachers in an era of high-stakes testing. Psychology in the Schools, 45(3), 206-216. 